\title{
Regulatory T Cells and Their Derived Cytokine, Interleukin-35, Reduce Pain in Experimental Autoimmune Encephalomyelitis
}

\author{
Samuel S. Duffy, ${ }^{1}$ Brooke A. Keating, ${ }^{1}$ Chamini J. Perera, ${ }^{1}$ Justin G. Lees, ${ }^{1}$ Ryan S. Tonkin, ${ }^{1}$ Preet G.S. Makker, ${ }^{1}$ \\ Pascal Carrive, ${ }^{1}$ Oleg Butovsky, ${ }^{2}$ and Gila Moalem-Taylor ${ }^{1}$ \\ ${ }^{1}$ School of Medical Sciences, The University of New South Wales, UNSW Sydney, Sydney, New South Wales 2052, Australia, and ${ }^{2}$ Ann Romney Center for \\ Neurologic Diseases, Brigham and Women's Hospital, Harvard Medical School, Boston, Massachusetts 02115
}

Sensory problems such as neuropathic pain are common and debilitating symptoms in multiple sclerosis (MS), an autoimmune inflammatory disorder of the CNS. Regulatory T (Treg) cells are critical for maintaining immune homeostasis, but their role in MS-associated pain remains unknown. Here, we demonstrate that Treg cell ablation is sufficient to trigger experimental autoimmune encephalomyelitis (EAE) and facial allodynia in immunized female mice. In EAE-induced female mice, adoptive transfer of Treg cells and spinal delivery of the Treg cell cytokine interleukin-35 (IL-35) significantly reduced facial stimulus-evoked pain and spontaneous pain independent of disease severity and increased myelination of the facial nociceptive pathway. The effects of intrathecal IL-35 therapy were Treg-cell dependent and associated with upregulated IL-10 expression in CNS-infiltrating lymphocytes and reduced monocyte infiltration in the trigeminal afferent pathway. We present evidence for a beneficial role of Treg cells and IL-35 in attenuating pain associated with EAE independently of motor symptoms by decreasing neuroinflammation and increasing myelination.

Key words: experimental autoimmune encephalomyelitis; IL-35; multiple sclerosis; neuroinflammation; neuropathic pain; regulatory T cells

\section{Significance Statement}

Pain is a highly prevalent symptom affecting the majority of multiple sclerosis (MS) patients and dramatically affects overall health-related quality of life; however, this is a research area that has been largely ignored. Here, we identify for the first time a role for regulatory T (Treg) cells and interleukin-35 (IL-35) in suppressing facial allodynia and facial grimacing in animals with experimental autoimmune encephalomyelitis (EAE). We demonstrate that spinal delivery of Treg cells and IL-35 reduces pain associated with EAE by decreasing neuroinflammation and increasing myelination independently of motor symptoms. These findings increase our understanding of the mechanisms underlying pain in EAE and suggest potential treatment strategies for pain relief in MS.

\section{Introduction}

Multiple sclerosis (MS) is a chronic inflammatory demyelinating disease of the CNS, with an estimated global prevalence of 2.5

Received July 17, 2018; revised Dec. 18, 2018; accepted Jan. 6, 2019.

Author contributions: S.S.D. wrote the first draft of the paper; S.S.D., B.A.K., C.J.P., J.G.L., R.S.T., P.G.S.M., P.C., 0.B., and G.M.-T. edited the paper; S.S.D., P.C., and G.M.-T. designed research;S.S.D., B.A.K., and C.J.P. performed research; 0.B. contributed unpublished reagents/analytic tools; S.S.D., B.A.K., J.G.L., R.S.T., P.G.S.M., and G.M.-T. analyzed data; S.S.D. and G.M.-T. wrote the paper.

This work was supported in part by the National Health and Medical Research Council of Australia (Grant APP1045343 to G.M.-T.). We thank Christopher Brownlee and Emma Johansson Beves for assistance with FACS; Munawwar Abdulla for assistance in scoring facial grimacing images; and Jason Potas and Boaz Shulruffor statistical advice.

The authors declare no competing financial interests.

Correspondence should be addressed to Gila Moalem-Taylor at gila@unsw.edu.au. million people (Browning et al., 2012). MS is a major cause of neurological disability in young adults (Rolak, 2003) and is characterized by inflammatory lesions within the CNS caused by autoimmune inflammation, demyelination, gliosis, and neurodegeneration leading to a disruption of neuronal signaling (Dendrou et al., 2015). The presentation of MS is heterogenous, with patients showing a wide range of neurological symptoms dependent on the spatiotemporal distribution of lesions in the CNS. Symptoms may appear in a relapsing-remitting pattern or as a steady progression and include sensory and motor disturbances, cognitive impairment, fatigue, and pain (Duffy et al., 2018b). 
Despite the fact that pain afflicts $\sim 67 \%$ of patients (Drulovic et al., 2015) and limits activities of daily living in $62 \%$ of patients (Feketova et al., 2016), it remains an understudied symptom with largely inadequate treatment options.

Experimental autoimmune encephalomyelitis (EAE) is the most widely used animal model of MS and mice with EAE develop robust stimulus-evoked pain behaviors including thermal hyperalgesia, and mechanical and cold allodynia of the tail, hindpaws, forepaws, and face (Aicher et al., 2004; Olechowski et al., 2009; Rodrigues et al., 2009; Lu et al., 2012; Yuan et al., 2012; Schmitz et al., 2013; Duffy et al., 2016; Thorburn et al., 2016). Mice with EAE also develop spontaneous pain measured using the mouse grimace scale (MGS) (Duffy et al., 2016). Although the exact mechanisms underlying pain in MS and EAE are unclear, demyelination and neuroinflammation in nervous system areas involved in pain processing, such as the dorsal horn and spinothalamic pathway, have been implicated (Moalem and Tracey, 2006; Olechowski et al., 2009; Truini et al., 2013). Therefore, targeted immunosuppression and remyelination represent novel strategies in the treatment of MS-associated pain.

Regulatory $\mathrm{T}$ (Treg) cells expressing the forkhead box protein 3 (FoxP3) transcription factor play a pivotal role in maintaining self-tolerance and inhibiting autoimmunity. Treg cells exert their suppressive function by multiple mechanisms including cytolysis of effector cells, metabolic disruption of T-cell proliferation, modulation of antigen-presenting cell function, and the release of anti-inflammatory cytokines transforming growth factor-beta (TGF- $\beta$ ), interleukin-10 (IL-10), and IL-35 (Collison et al., 2007; Duffy et al., 2018a). Unlike IL-10, which has been demonstrated to significantly attenuate mechanical allodynia in EAE (Sloane et al., 2009; Grace et al., 2017), little is known about the effects of IL-35 in pain associated with EAE. IL-35, the most recently discovered IL-12 family member, is a heterodimeric cytokine composed of p35 and EBI3 and its action appears to be purely immunosuppressive (Collison and Vignali, 2008). IL-35 is produced primarily by Treg cells (Collison et al., 2007), but also by B cells (Shen et al., 2014; Wang et al., 2014) and tolerogenic dendritic cells (Dixon et al., 2015), and is capable of inhibiting T-cell proliferation (Collison et al., 2007), as well as inducing the conversion of naive $\mathrm{T}$ cells into IL-35-producing induced Treg (iTr35) cells (Collison et al., 2010). Treg-cell activation generates distinct effector IL-35-producing and IL-10-producing Treg cell subsets, which work cooperatively to maintain immune tolerance (Wei et al., 2017). Although Treg cells are known negative modulators of inflammation, they have also recently been shown to exert direct regenerative effects in the CNS by promoting remyelination, an effect independent of their immunomodulatory function (Dombrowski et al., 2017).

In this study, we tested the hypothesis that treatment with Treg cells and IL-35 limits pain in EAE. We found that depletion of FoxP $3^{+}$Treg cells in mice time dependently triggers severe EAE and increases pain behaviors. Conversely, adoptive transfer of activated Treg cells and intrathecal injection of IL-35 resulted in decreased facial allodynia and facial grimacing independently of motor symptoms, as well as in decreased neuroinflammation and increased myelination of the facial nociceptive pathway. These findings have important implications for the management of pain in MS.

\section{Materials and Methods}

Animals. Female C57BL/6J mice or DEPletion of REGulatory T cell (DEREG) mice (Lahl et al., 2007) (Australian Biological Resources) aged $10-18$ weeks were used in all experiments. Mice were housed in individ- ually ventilated cages with water and food ad libitum in groups of three to five and maintained on a $12 \mathrm{~h}$ light/dark cycle. The facility was kept at a constant room temperature and humidity and the animals were monitored daily throughout experiments. All experiments were approved by the Animal Care and Ethics Committee of the University of New South Wales (Sydney, Australia).

EAE induction and assessment. EAE was induced by subcutaneous immunization with myelin oligodendrocyte glycoprotein (MOG) $35-55$ emulsified in complete Freund's adjuvant (CFA). Emulsions were purchased from Hooke Laboratories as prefilled syringes, each containing $\sim 1 \mathrm{mg} / \mathrm{ml} \mathrm{MOG}_{35-55}$ emulsified with 2-5 mg of killed Mycobacterium tuberculosis $\mathrm{H} 37 \mathrm{Ra} / \mathrm{ml}$ in incomplete Freund's adjuvant. Control mice were immunized with CFA alone (Hooke Laboratories) at the same concentration given to mice immunized with $\mathrm{MOG}_{35-55} / \mathrm{CFA}$. Immunizations were given under $3-5 \%$ isoflurane anesthesia in oxygen as $2 \times 100$ $\mu l$ subcutaneous injections; one either side of the spinal column on the lower back (final dose of $200 \mu \mathrm{g} \mathrm{MOG}_{35-55}+400-1000 \mu \mathrm{g} \mathrm{M.} \mathrm{tubercu-}$ losis in CFA per $200 \mu \mathrm{l} /$ mouse). An intraperitoneal injection of $200 \mathrm{ng}$ pertussis toxin (PTx) (Hooke Laboratories) in $100 \mu$ l of Dulbecco's PBS (D-PBS; Life Technologies) was given to all mice 2-6 h after subcutaneous immunization and again $22-26 \mathrm{~h}$ later.

In experiments incorporating Treg-cell depletion, a modified EAE induction protocol was used whereby DEREG and WT mice were immunized with $\mathrm{MOG}_{35-55} / \mathrm{CFA}$ without the use of PTx injections (termed EAEnp). Treg-cell depletion in DEREG mice has been shown to result in fatal EAE using a standard induction protocol using $\mathrm{MOG}_{35-55} / \mathrm{CFA}$ immunization and PTx injection (Koutrolos et al., 2014) and our modified induction protocol produced milder clinical disease, which allowed for the exacerbating effects of Treg-cell depletion in DEREG mice without mortality. For these experiments, a 1:1 $\mathrm{MOG}_{35-55} / \mathrm{CFA}$ emulsion was prepared by mixing $1 \mathrm{mg} / \mathrm{ml} \mathrm{MOG}_{35-55}$ (Prospec) in sterile water with CFA. CFA was prepared as $2.5 \mathrm{mg} / \mathrm{ml}$ killed M. tuberculosis $\mathrm{H} 37 \mathrm{Ra} / \mathrm{ml}$ (BD Difco) in incomplete Freund's adjuvant (Sigma-Aldrich). Immunizations were given under $3-5 \%$ isoflurane anesthesia in oxygen as $2 \times$ $100 \mu \mathrm{l}$ subcutaneous injections, one either side of the spinal column on the lower back (final dose of $200 \mu \mathrm{g} \mathrm{MOG}_{35-55}+500 \mu \mathrm{g}$ of M. tuberculosis in CFA per $200 \mu \mathrm{l} /$ mouse).

After induction, mice were monitored daily for body weight and EAE clinical scores according to a detailed EAE grading system supplied by Hooke Laboratories. Briefly, EAE clinical scores were assigned as follows: Grade 1 = limp tail; Grade 2 = limp tail and weakness of hind legs; Grade $3=$ limp tail and complete paralysis of hind legs or limp tail with paralysis of one front and one hind leg; Grade $4=$ limp tail, complete hind leg and partial front leg paralysis; and Grade $5=$ complete hind and complete front leg paralysis. If mice reached a score of 4 , they were immediately killed and a score of 4 was recorded for the remainder of the monitoring period for that animal.

Measurement of facial allodynia. In the week before baseline behavioral testing, mice were handled daily using a cotton glove to gradually acclimatize them to being gently restrained in the experimenter's hand. Before testing, the same experimenter gently restrained the mouse in their palm with the head exposed using the cotton glove until the mouse was acclimated and calm. During testing, a second experimenter blinded to experimental groups applied a $0.07 \mathrm{~g}$ von Frey filament to the whisker pad 5 times per side with a 1 min interval between tests. Responses were recorded as head withdrawal, forepaw swiping, or facial flinching by a blinded experimenter. A percentage of total responses over the five tests per side were calculated for each animal.

$M G S$. During MGS testing, mice were placed in a $5 \times 5 \times 10 \mathrm{~cm}$ plastic arch with glass windows at each end placed on an elevated wire mesh, with two Canon 500D cameras positioned at each end for high definition video recording. Mice were filmed for $11 \mathrm{~min}$ total and screen grabs were later taken at each minute mark following beginning of recording for a total of 10 photos per mouse. These were taken as soon as a clear head shot could be observed and scored according to the criteria developed by Langford et al. (2010) with the omission of the whisker change action unit because this was deemed difficult in $\mathrm{C} 57 \mathrm{BL} / 6 \mathrm{~J}$ mice due to coat color. Mean MGS scores were calculated by an experimenter blinded to treatment groups. 
Depletion of FoxP3 ${ }^{+}$Treg cells in DEREG mice. For specific ablation of Treg cells, DEREG mice were used. These transgenic mice allow for selective FoxP ${ }^{+}$cell depletion with minimal off-target side effects (Lahl et al., 2007; Lahl and Sparwasser, 2011) following injection with diphtheria toxin (DTx) (Merck-Millipore). This was delivered as an intraperitoneal injection of $500 \mathrm{ng}$ of DTx dissolved in $100 \mu \mathrm{l}$ of D-PBS, which was previously shown to result in significant depletion of FoxP3 ${ }^{+}$Treg cells in DEREG mice (Lees et al., 2015).

FACS of $\mathrm{GFP}^{+}$Treg cells from DEREG mice. At day 30 after EAE induction, DEREG donor mice were anesthetized using 3-5\% isoflurane in oxygen. The inguinal lymph nodes (ILNs), cervical lymph nodes (superficial and deep; CLNs), and spleens were then removed and placed into 7 $\mathrm{ml}$ of Hank's balanced salt solution (HBSS) containing $0.5 \%$ fetal bovine serum (FBS; Invitrogen), $20 \mathrm{~mm}$ HEPES (Invitrogen), and $1 \times 10,000$ $\mathrm{U} / \mathrm{ml}$ penicillin-streptomycin (Invitrogen) at room temperature (RT). Mice were killed using $0.1 \mathrm{ml}$ of Lethabarb (Virbac). Pooled lymph nodes (LNs), spleens, and collecting media were mechanically ground through $70 \mu \mathrm{m}$ cell strainers (BD Biosciences). Cell suspensions were centrifuged for $5 \mathrm{~min}$ at $300 \times g$ at RT before discarding the supernatant. Cells were then resuspended in $5 \mathrm{ml}$ of red blood cell (RBC) lysis buffer (Alfa Aesar), agitated for $5 \mathrm{~min}$ at RT, and $8 \mathrm{ml}$ of HBSS was added to each sample. Cells were centrifuged at RT for $5 \mathrm{~min}$ at $300 \times g$, the supernatant was discarded, and cells were washed once with RPMI-1640 (Invitrogen) with $5 \%$ FBS (Invitrogen) $(300 \times g, 5 \mathrm{~min}, \mathrm{RT})$. Cells were then resuspended in $8 \mathrm{ml}$ of RPMI-1640 (Invitrogen) with 5\% FBS (Invitrogen) prewarmed to $37^{\circ} \mathrm{C}$ in a $50 \mathrm{ml}$ flask. Samples were incubated at $37^{\circ} \mathrm{C}$ with $5 \% \mathrm{CO}_{2}$ for $1 \mathrm{~h}$ to allow adherence of monocytes. Medium with nonadherent cells was removed, put into a $15 \mathrm{ml}$ tube, and centrifuged at RT for $5 \mathrm{~min}$ at $300 \times \mathrm{g}$. Cells were then resuspended in $4 \mathrm{ml}$ of HBSS (Invitrogen) with $2 \%$ FBS (Invitrogen), 20 mM HEPES (Invitrogen), and $1 \times$ $10,000 \mathrm{U} / \mathrm{ml}$ penicillin-streptomycin (Invitrogen) and green fluorescent protein-positive $(\mathrm{GFP})^{+}$cells were sorted using FACS on a FACSAria III cell sorter (BD Biosciences).

In vitro activation of $\mathrm{GFP}^{+}$Treg cells. Sorted $\mathrm{GFP}^{+}$cells from DEREG mice were suspended in medium containing RPMI-1640 (Invitrogen) with 5\% FBS (Invitrogen), 10 mM HEPES (Invitrogen), $1 \times$ nonessential amino acid (NEAA) supplement (Invitrogen), $1 \times$ sodium pyruvate (Invitrogen), $1 \times \beta$ mercaptoethanol (Invitrogen), and $1 \times 10,000 \mathrm{U} / \mathrm{ml}$ penicillin-streptomycin (Invitrogen) at a concentration of $5 \times 10^{5}$ cells $/ \mathrm{ml}$ of medium. Then, $200 \mu$ l of cells $\left(1 \times 10^{5}\right.$ cells $)$ was added to individual wells of a 96-well plate, along with CD3/CD28 Dynabeads (Invitrogen) at a 1:1 ratio to cells and mouse recombinant IL-2 at a concentration of $50 \mathrm{ng} / \mathrm{ml}$ (R\&D Systems). Cells were incubated for $7 \mathrm{~d}$ at $37^{\circ} \mathrm{C}$ with $5 \% \mathrm{CO}_{2}$.

Adoptive transfer of activated $\mathrm{GFP}^{+}$Treg cells. Following the $7 \mathrm{~d}$ in vitro activation, cells were transferred from the 96 -well plate to $1.5 \mathrm{ml}$ tubes. Cells were vortexed to allow dissociation of cells and CD3/CD28 beads and beads were removed from the medium using magnetic separation. Cells were then centrifuged to remove the medium $(600 \times g$, $5 \mathrm{~min}$ at $\mathrm{RT}$ ), and resuspended in sterile D-PBS for injection into recipient mice. Then, $2 \times 10^{6}$ cells in $100 \mu$ l of D-PBS were injected in intraperitoneal adoptive transfer experiments and $0.5 \times 10^{6}$ cells in $5 \mu$ l of D-PBS were injected in intrathecal adoptive transfer experiments. Control groups were injected with D-PBS alone. Intrathecal injections were delivered under $3-5 \%$ isoflurane anesthesia in oxygen via lumbar puncture between the L5 and L6 vertebrae.

$I L-35$ ELISA. Mice were anesthetized using 3-5\% isoflurane in oxygen and then killed using $0.1 \mathrm{ml}$ of Lethabarb (Virbac) intraperitoneally and transcardially perfused with heparinized $0.9 \%$ saline solution. The brain and spinal cord were dissected and snap-frozen in liquid nitrogen. Samples were then stored at $-80^{\circ} \mathrm{C}$ until further processing. Frozen tissue was then homogenized using scissors in an ice-cold lysis buffer (Total Protein Extraction Kit; Millipore). The tissue lysate was then transferred to tubes containing $1.5 \mathrm{~mm}$ ceramic beads and homogenized in a cooled Precellys 24 machine with the Cryolys cooling option (Bertin Instruments) and then rotated in a cold room at $4^{\circ} \mathrm{C}$ for $20 \mathrm{~min}$. Samples were then centrifuged at $11,000 \times g$ for $20 \mathrm{~min}$ at $4^{\circ} \mathrm{C}$ and total protein per sample was quantified using a BCA protein assay kit (Thermo Scientific). Then, $500 \mu \mathrm{g}$ of protein per nervous system sample was added to a
LEGEND MAX mouse IL-35 heterodimer ELISA kit (BioLegend), and the assay performed according to the manufacturer's protocol.

Intrathecal IL-35 therapy. Mouse recombinant IL-35 consisting of the extracellular domain of the mouse IL-12a subunit fused to the Fc region of human IgG1 and the mouse Epstein-Barr virus induced gene 3 (EBI3) subunit linked to IL-12a by disulfide bonds was used (Chimerigen). This was delivered under 3-5\% isoflurane anesthesia in oxygen via an intrathecal injection between the L5 and L6 vertebrae as $0.1 \mu \mathrm{g}$ of IL-35 dissolved in $5 \mu \mathrm{l}$ of sterile D-PBS or as $5 \mu \mathrm{l}$ of D-PBS alone for control groups, per injection.

Flow cytometry. At designated end points after EAE induction, mice were anesthetized using 3-5\% isoflurane in oxygen. The spleens, ILNs, and CLNs, were then removed and placed into PBS on ice. Mice were killed using $0.1 \mathrm{ml}$ of Lethabarb (Virbac) injected intraperitoneally and transcardially perfused with heparinized $0.9 \%$ saline solution. The dorsal root ganglia (DRG), spinal cords, brains or brainstems (caudal medulla to rostral pons) were then dissected and placed into PBS on ice. Nervous system tissue was coarsely chopped and incubated with $1 \mathrm{ml}$ of Accutase (Sigma-Aldrich) for $30 \mathrm{~min}$ at $37^{\circ} \mathrm{C} 5 \% \mathrm{CO}_{2}$. Nervous system tissue was then mechanically ground through $70 \mu \mathrm{m}$ cell strainers (BD Biosciences) in $10 \mathrm{ml}$ of PBS and LNs were crushed using a pestle and passed through a $40 \mu \mathrm{m}$ cell strainers (BD Biosciences) in $10 \mathrm{ml}$ of PBS. Spleen samples were resuspended in $5 \mathrm{ml}$ of RBC lysis buffer (Alfa Aesar), agitated for 5 min at RT, and $8 \mathrm{ml}$ of HBSS was added to each sample. All cell suspensions (LNs, spleens, and nervous tissue) were centrifuged for $5 \mathrm{~min}$ at $1000 \times g$ at $4^{\circ} \mathrm{C}$ before discarding the supernatant. Then, $10 \mathrm{ml}$ of $30 \%$ Percoll (GE Healthcare) in PBS was added to each nervous system sample, which was then centrifuged for $25 \mathrm{~min}$ at $600 \times g$ at RT. From these samples, the supernatant, including the myelin/cell debris layer, was carefully removed using a pipette. All samples were then resuspended in autoMACS (Miltenyi Biotec) running buffer and counted to give a final cell concentration of $\sim 1 \times 10^{7}$ cells $/ \mathrm{ml}$. In antibody panels incorporating staining of intracellular cytokines and not assessing the Treg cell phenotype, cells underwent activation before staining using a cell activation mixture consisting of phorbol 12-myristate-13-acetate (PMA), ionomycin, and the protein transport inhibitor brefeldin A (BioLegend). In these cases, cells were incubated at a concentration of $2 \times 10^{6} \mathrm{cells} / \mathrm{ml}$ in RPMI-1640 (Invitrogen) with 10\% FBS (Invitrogen) and $1 \times$ cell activation mixture (BioLegend) for $4 \mathrm{~h}$ at $37^{\circ} \mathrm{C}$ with $5 \% \mathrm{CO}_{2}$.

A total of $100 \mu \mathrm{l}$ of cells $\left(\sim 1 \times 10^{6}\right.$ cells $)$ were stained per sample. When stated, Zombie Violet or Zombie UltraViolet cell viability dye (BioLegend; 1:100) was added to samples in $100 \mu$ l of PBS, which were then incubated in the dark for $15 \mathrm{~min}$ at RT. Extracellular antibodies were diluted in $100 \mu \mathrm{l}$ of autoMACS running buffer to give a total staining volume of $200 \mu \mathrm{l}$ and cells were incubated for $30 \mathrm{~min}$ at $4^{\circ} \mathrm{C}$ in the dark. These antibodies included anti-CD4-FITC (eBioscience; 1:1000), anti-CD4-BV711 (BioLegend; 1:1000), anti-CD8-PE/Cy7 (BioLegend; 1:1000), anti-CD19-PerCP/Cy5.5 (BioLegend; 1:400), anti-CD25-PE/ Dazzle (BioLegend; 1:400), anti-CD39-PerCPeFluor710 (eBioscience; 1:400), and anti-LAP-BV421 (BioLegend; 1:100). After staining, samples were washed 3 times $\left(600 \times g, 5 \mathrm{~min}\right.$ at $\left.4^{\circ} \mathrm{C}\right)$ in $1 \mathrm{ml}$ of autoMACS running buffer before being resuspended in $1 \mathrm{ml}$ of fixation solution (eBioscience) and left at $4^{\circ} \mathrm{C}$ overnight.

Samples were centrifuged $\left(600 \times g, 5 \mathrm{~min}, 4^{\circ} \mathrm{C}\right)$ and washed twice in 1 $\mathrm{ml}$ of permeabilization solution (eBioscience) before adding all intracellular antibodies diluted in $100 \mu \mathrm{l}$ of permeabilization solution to give a total staining volume of $200 \mu \mathrm{l}$ and incubating for $30 \mathrm{~min}$ at RT in the dark. These antibodies included anti-FoxP3-PE/Cy7 (eBioscience; 1:200), anti-IFN- $\boldsymbol{\gamma}$-APC (BioLegend; 1:100), anti-IL-17a-PE (BioLegend, 1:200), anti-IL-10-BV605 (BioLegend; 1:100), anti-IL-10-PerCP/ Cy5.5 (BioLegend; 1:100), anti-IL-4-PerCP/Cy5.5 (BioLegend; 1:100), anti-p35-APC (R\&D Systems; 1:20), and anti-EBI3-PE (R\&D Systems; 1:20). Samples were then washed 3 times $\left(600 \times g, 5 \mathrm{~min}\right.$ at $\left.4^{\circ} \mathrm{C}\right)$ in $1 \mathrm{ml}$ of permeabilization solution, resuspended in $200 \mu \mathrm{l}$ of autoMACS running buffer, and analyzed on a FACS Canto II or FACS Fortessa-X20 flow cytometer (BD Biosciences). A minimum of 50,000 events were acquired per sample and data were analyzed using FlowJo software. Appropriate fluorescence minus one and/or isotype controls were included by staining pooled samples for each tissue analyzed. 
Tissue preparation for immunohistochemistry and myelin staining. At designated end points after EAE induction, mice were killed using $0.1 \mathrm{ml}$ of Lethabarb (Virbac) and transcardially perfused with heparinized $0.9 \%$ saline solution followed by $10 \%$ formalin solution (Sigma-Aldrich). The brain (including brainstem) was then dissected and postfixed in formalin solution overnight at $4^{\circ} \mathrm{C}$. The brainstem (caudal medulla to rostral pons) was then dissected from the brain and all tissues were transferred to $30 \%$ sucrose $+0.1 \%$ sodium azide solution and stored at $4^{\circ} \mathrm{C}$ until sectioning. Sections were cut coronally using a cryostat (Leica Biosystems) at a thickness of $20 \mu \mathrm{m}$. All sections were cut sequentially such that each slide contained four to eight serial sections representative of the entire thickness of the tissue. Each slide contained eight representative sections of the entire spinal and principle trigeminal nuclei: two of the subnucleus caudalis, two of the subnucleus interpolaris, two of the subnucleus oralis, and two of the principle trigeminal nucleus. Sections were transferred directly to gelatin-coated glass slides, air dried overnight, and stored at $-80^{\circ} \mathrm{C}$ until staining.

Immunohistochemistry. Before staining, sections were fixed with ethanol for $10 \mathrm{~min}$ at RT. Sections were then washed twice with distilled water and once with PBS containing $0.05 \%$ Tween 20 (PBS-T). A blocking solution containing PBS with 5\% donkey serum (Sigma-Aldrich), 0.2\% Tween 20 , and $0.3 \%$ Triton X-100 was applied to each slide for incubation at RT for $1 \mathrm{~h}$ in the dark. The blocking solution was drained and sections were incubated with the following primary antibodies diluted in PBS containing 5\% bovine serum albumin and $0.03 \%$ Triton X-100: rabbit anti-mouse/rat IBA-1 (ionized calcium-binding adapter molecule 1; macrophages/microglia; 1:2000; Wako Chemicals), mouse anti-mouse GFAP (glial fibrillary acidic protein; astrocytes; 1:2000; Millipore Bioscience Research Reagents), rabbit anti-mouse P2ry12 (resident homeostatic microglia; 1:500; generated by Dr. Oleg Butovsky), and rat anti-mouse 4C12 (infiltrating monocytes; 1:1000; generated by Dr. Oleg Butovsky). IBA-1 and GFAP primary antibody incubation was conducted at RT for $1 \mathrm{~h}$, whereas all other primary antibodies were incubated overnight at $4^{\circ} \mathrm{C}$.

Sections were then washed 4 times with PBS-T for 10 min each before adding secondary antibodies, which included: Alexa Fluor 488conjugated donkey anti-mouse (1:1000; Life Technologies), Alexa Fluor 488 donkey anti-rat (1:1000; Life Technologies), or Alexa Fluor 546conjugated donkey anti-rabbit (1:1000; Life Technologies) in the same buffer as the primary antibody. Negative staining controls were incorporated in which tissues were incubated with secondary antibody alone in the absence of the relevant primary antibody (to control for nonspecific binding of the secondary antibody). Following a $1 \mathrm{~h}$ incubation at RT in the dark, sections were washed 4 times in PBS-T for 10 min each. Prolong gold anti-fade reagent with 4', 6-diamidino-2-phenylindole (DAPI; Life Technologies) was applied before slides were coverslipped and stored at $4^{\circ} \mathrm{C}$ until viewing.

Black Gold II myelin staining. For quantification of myelin in the spinal trigeminal tract, Black Gold II myelin staining was used (MerckMillipore). $0.3 \%$ Black-Gold II and 1\% sodium thiosulfate solutions were preheated to $60^{\circ} \mathrm{C}$ in glass Coplin jars. Sections were rehydrated in Milli-Q water (Millipore) for $2 \mathrm{~min}$ and then transferred to the preheated Black Gold II solutions and incubated at $60^{\circ} \mathrm{C}$. After $15 \mathrm{~min}$, sections were washed twice in Milli-Q water for 2 min each before being transferred to the preheated sodium thiosulfate solution and incubated at $60^{\circ} \mathrm{C}$. After $3 \mathrm{~min}$, sections were washed 3 times in Milli-Q water for 2 min each. Sections were then dehydrated by consecutive 1 min incubations in $70 \%, 95 \%$, and $100 \%$ ethanol for $1 \mathrm{~min}$ each at RT. Finally, sections were cleared for $1 \mathrm{~min}$ in xylene at RT, coverslipped with DPX mounting medium (VWR International), and stored at $4^{\circ} \mathrm{C}$ until viewing.

Image analysis. Analysis of images was conducted blinded to experimental groups from which the tissue was derived. Slides containing eight sections of trigeminal nucleus (extending from subnucleus caudalis to principle nucleus) per animal were used for a given antibody/stain. Images were taken at $20 \times$ magnification of left and right trigeminal nucleus regions (four images each of the subnucleus caudalis, subnucelus interpolaris, subnucleus oralis, and principle nucleus for a total of 16 images per animal/slide) or at $10 \times$ magnification for the left and right spinal trigeminal tract (a total of 16 images per animal/slide). The number of images taken at each level of the brainstem trigeminal nuclei was consistent between animals and experimental groups. GFAP, IBA-1, P2ry12, and Black Gold II myelin staining was quantified by calculating the percentage of total reactive area after subtracting background area. The spinal trigeminal tract was first gated to exclude gray matters regions in Black Gold II myelin analyses. 4C12 staining was calculated by counting the number of immunoreactive cells per area. All images were analyzed using ImageJ software and values for each trigeminal nucleus/tract region were averaged across sections to give the mean reactivity per animal.

Image acquisition. All images were viewed using an Olympus BX51 epifluorescence microscope and captured using an Olympus DP73 camera using cellSens software (Olympus). All images for a particular stain were taken using identical microscope settings.

Experimental design and statistical analysis. In animal experiments, mice were randomly assigned into a control CFA-immunized group, a MOG-immunized vehicle-treated EAE group, or a MOG-immunized Treg- or IL-35-treated EAE group. Details of specific experimental design, data collection, and experimenter blinding have been provided under each individual technique throughout the Materials and Methods section. All statistical analyses were conducted using GraphPad Prism 7 software. EAE clinical scores and body weight were analyzed using repeated-measures two-way ANOVA (treatment and time) with Tukey's post hoc test. Allodynia testing proved to be not normally distributed using a Shapiro-Wilk normality test and a Kruskal-Wallis test with Dunn's post hoc test was used as the most appropriate statistical test. The Holm-Bonferroni correction for multiple comparisons was then used to account for repeated testing. MGS and immunohistochemistry/myelin staining data were analyzed using a one-way ANOVA with Tukey's post hoc test. Heteroscedastic datasets were identified using Bartlett's test and $\log$ transformed before statistical analysis. This was conducted in MGS analyses in Figures 7 and 14 and 4C12 analyses in Figures 8 and 12. Flow cytometry data were analyzed using an unpaired two-tailed Student's $t$ test (when comparing two groups) or a one-way ANOVA with Tukey's post hoc test (when comparing $>2$ groups). Multiple time point flow cytometry data were analyzed using two-way ANOVA (treatment and time) with Tukey's post hoc test. Cell proliferation measured using preand post-in vitro CD3/CD28 and IL-2 activation was analyzed using a paired two-tailed $t$ test. ELISA results were analyzed using two-way ANOVA (treatment and tissue) with Tukey's post hoc test. Allodynia data analyzed using nonparametric statistical tests are presented as box-andwhisker plots, in which box limits show the first and third quartile, the center line is the median, and the whiskers represent the minimum and maximum values. EAE clinical score, body weight, MGS, flow cytometry, ELISA, cell count, and immunohistochemistry/myelin staining data are presented as arithmetic mean \pm SEM. The level of significance was set as $p<0.05$ for all analyses.

\section{Results}

Treg-cell depletion time dependently triggers severe EAE and increases facial allodynia

To assess the role of Treg cells in EAE and associated pain, we initiated our study with characterization of the levels of Treg cells, as well as effector pro-inflammatory and anti-inflammatory T-cell subsets, in the CNS over the course of chronic EAE. EAE mice were killed in the preclinical period (day 8), the clinical peak (day 16), or chronic phase (day 32) of EAE (Fig. 1A) and their spinal cords and brains analyzed using flow cytometry. Proinflammatory Th1 $\left(\mathrm{CD} 4{ }^{+} \mathrm{IFN}-\gamma^{+}\right.$; Fig. $\left.1 E\right)$ and Th17 cells $\left(\mathrm{CD} 4{ }^{+} \mathrm{IL}-17^{+}\right.$; Fig. $\left.1 I\right)$ were increased, whereas anti-inflammatory Th2 cells $\left(\mathrm{CD} 4{ }^{+} \mathrm{IL}-4^{+}\right.$; Fig. $\left.1 G\right)$ were decreased in the spinal cord and brain during the clinical stages of EAE compared with the preclinical period. Treg cells $\left(\mathrm{CD} 4{ }^{+} \mathrm{CD} 25^{+} \mathrm{FoxP} 3^{+}\right)$were increased in the spinal cord and brain during the clinical peak and chronic phase of EAE compared with the preclinical period $(p<$ $0.0001)$. Treg cells were also increased at day 32 compared with day 16 in the brain, in association with partial recovery from 
A

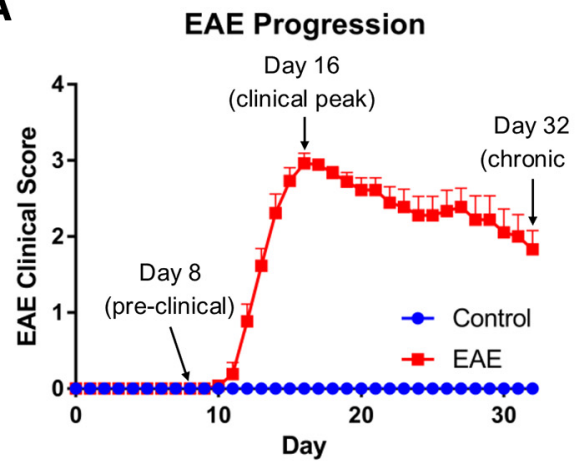

D

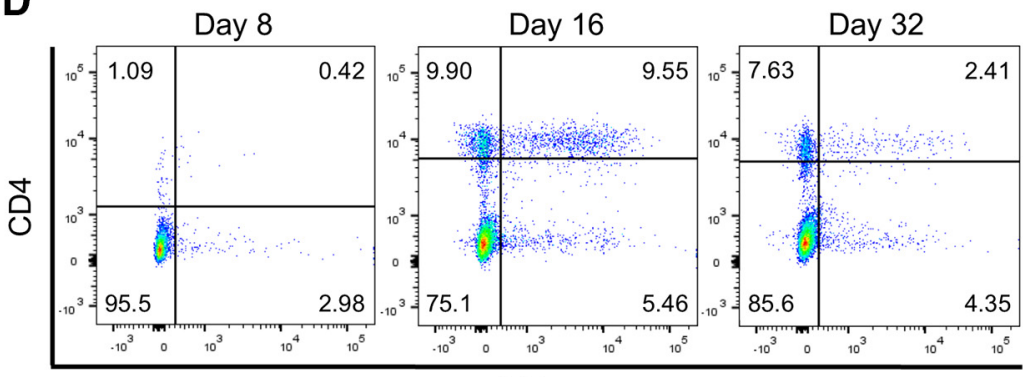

F

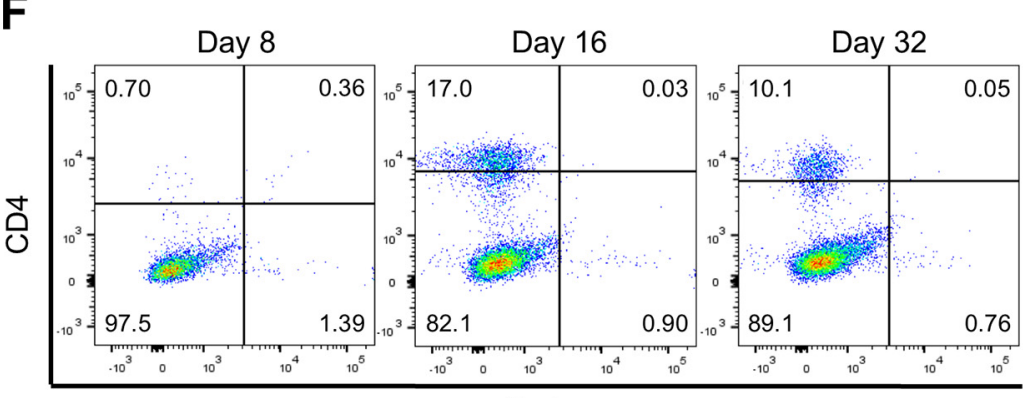

H

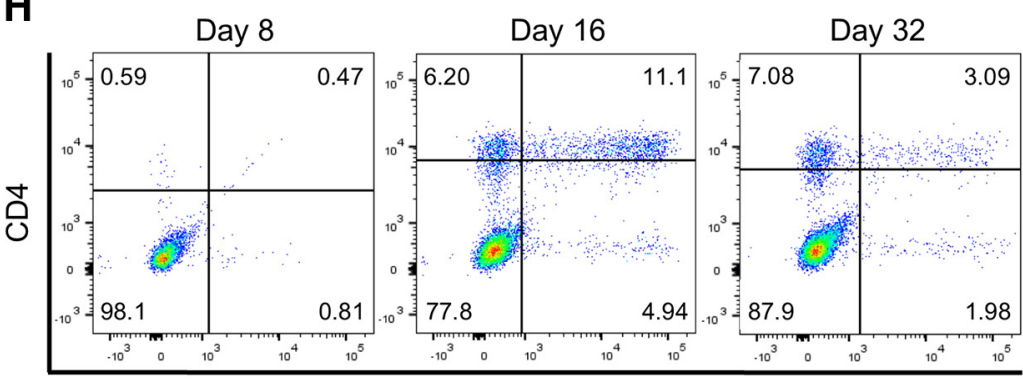

IL-17

J

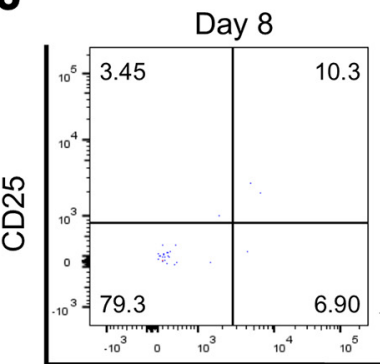

B

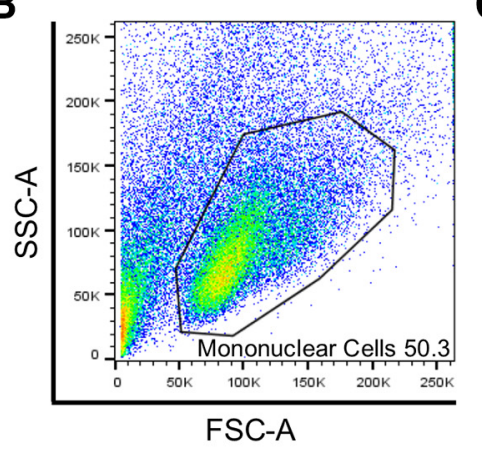

C

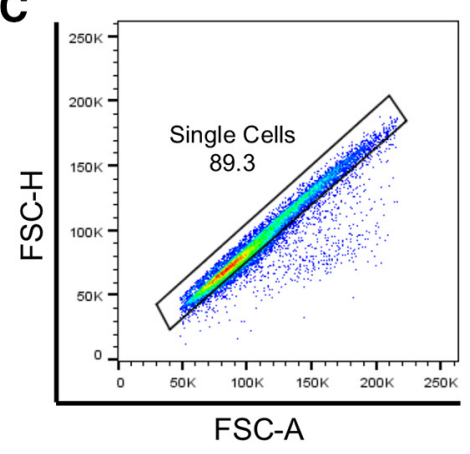

E

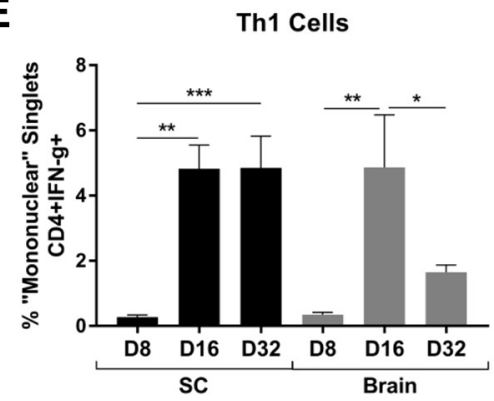

G

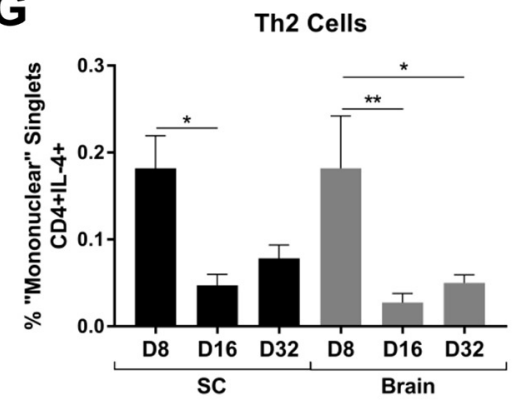

I

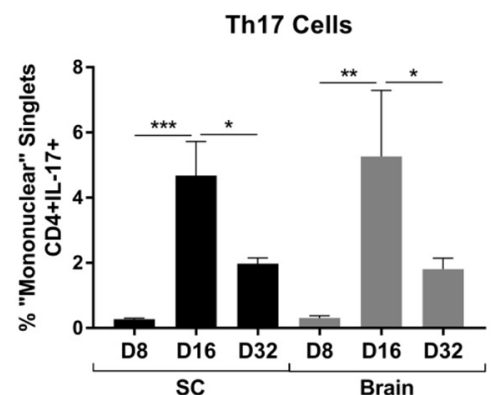

K

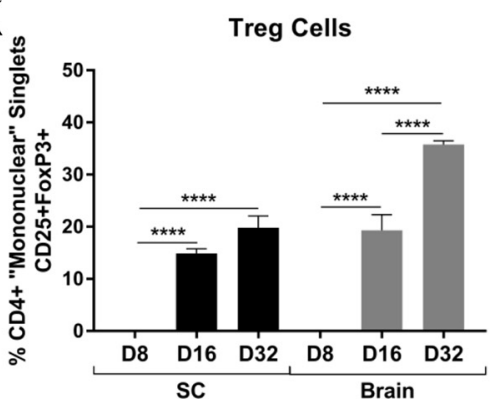

\section{FoxP3}

Figure 1. T-cell phenotyping in the CNS over the course of chronic EAE. Shown is an increase in Treg cells in the chronic phase associated with partial clinical recovery of disease. $A$, Disease progression over the $32 \mathrm{~d}$ monitoring period after induction in control and EAE mice and time points chosen for flow cytometric analysis of nervous tissue at preclinical, peak, and chronic phases of EAE $(n=12-13)$. Mononuclear cells were first gated $(\boldsymbol{B})$, followed by gating of singlets $(\boldsymbol{C})$ for further analysis. $\boldsymbol{D}$, Representative dot plots showing $\mathrm{CD}^{+}$IFN- $\gamma^{+}$(Th1) staining out of total mononuclear singlets at days 8, 16, and 32 after EAE induction. $\boldsymbol{E}$, Bar graph showing an increase in Th1 cells at day 16 and 32 compared with day 8 after EAE induction (Figure legend continues.) 


\section{A DEREG Treg Cell Depletion}

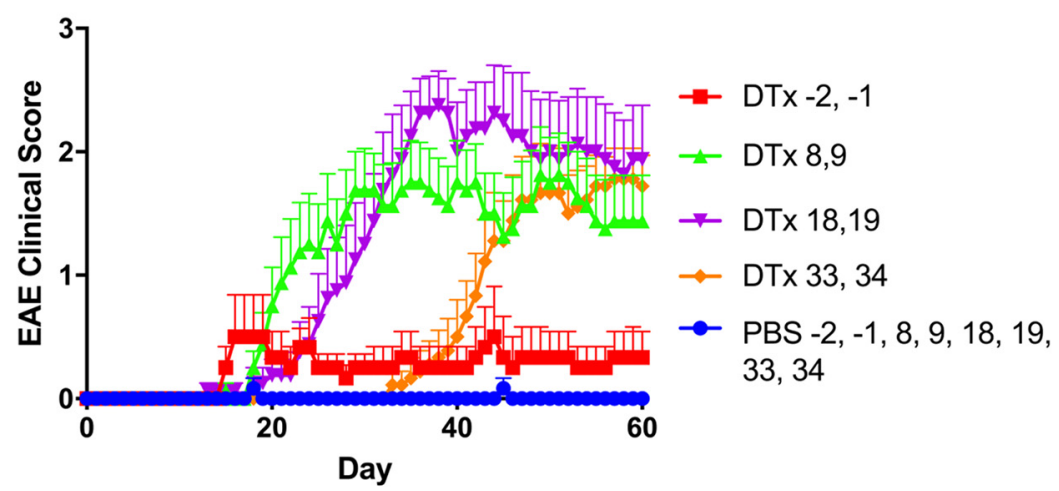

B

Facial Allodynia

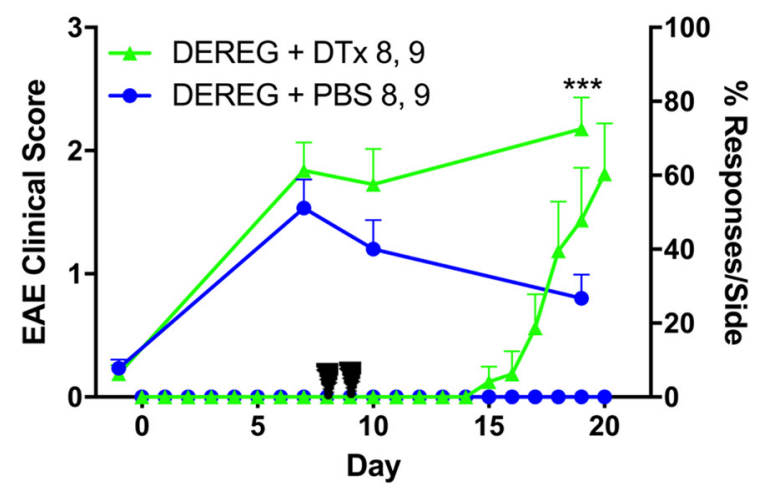

Figure 2. Treg-cell depletion time dependently triggers severe disease and increases facial allodynia in DEREG mice with EAEnp. $\boldsymbol{A}$, Disease progression of DEREG mice with EAEnp injected intraperitoneally with DTx on days -2 and $-1,8$ and 9,18 and 19 , and 33 and 34 or injected with PBS at all time points $(n=6-8)$. B, Increased facial allodynia was observed on day 19 after EAEnp induction in DEREG mice injected with DTx compared with those injected with PBS intraperitoneally on days 8 and $9 .{ }^{* *} p<0.001$, Kruskal-Wallis test with Dunn's post hoc test and Holm-Bonferroni correction for multiple comparisons, $n=8-9$. Data are expressed as mean \pm SEM.

clinical EAE at the chronic phase of the disease (Fig. $1 K ; p<$ $\left.0.0001, F_{(1,24)}=27.96\right)$.

To investigate the temporal effects of Treg cell ablation in EAE, we transiently depleted Treg cells at different time points over a mild form of EAE (induced without PTx injections), termed EAEnp, in DEREG mice. DTx was injected into DEREG mice to deplete Treg cells at days -2 and $-1,8$ and 9, 18 and 19, or 33 and 34 after EAEnp induction. Control EAEnp mice injected with PBS at all injection time points did not develop clinical symptoms over the $60 \mathrm{~d}$ monitoring period. Treg depletion at

\section{$\longleftarrow$}

(Figure legend continued.) in the spinal cord (SC). Th1 cells were also increased at day 16 compared with day 8 after EAE induction in the brain, but were decreased at day 32 compared with day $16 . F$, Representative dot plots out of total mononuclear singlets showing $\mathrm{CD} 4{ }^{+} \mathrm{IL}-4^{+}$ (Th2) staining at days 8, 16, and 32 after EAE induction. $G$, Bar graph showing a decrease in Th2 cells at day 16 compared with day 8 after EAE induction in the SC. Th2 cells were also decreased at day 16 and 32 compared with day 8 after EAE induction in the brain. $\boldsymbol{H}$, Representative dot plots out of total mononuclear singlets showing $\mathrm{CD}^{+}{ }^{+} \mathrm{IL}-17^{+}$(Th17) staining at days 8,16 , and 32 after EAE induction. $I$, Bar graph showing an increase in Th17 cells at day 16 compared with day 8, but a decrease at day 32 compared with day 16 after EAE induction in the SC and brain.J, Representative dot plots showing $\mathrm{CD} 25^{+} \mathrm{FoxP} 3^{+}$staining out of total $\mathrm{CD} 4{ }^{+}$mononuclear singlets at days 8, 16, and 32 after EAE induction. $\boldsymbol{K}$, Bar graph showing an increase in Treg cells at days 16 and 32 compared with day 8 in the SC and brain and an increase in Treg cells at day 32 compared with day 16 after EAE induction in the brain. ${ }^{*} p<0.05,{ }^{* *} p<0.01,{ }^{* * *} p<0.001$, ${ }^{* * * *} p<0.0001$, two-way ANOVA followed by Tukey's post hoc test, $n=4-6$. Data are expressed as mean \pm SEM. days -2 and -1 resulted in an extremely mild form of EAE with an average peak clinical score of 0.5 on day 16 after EAEnp induction. Treg depletion at days 8 and 9 resulted in EAE with an average peak clinical score of 1.8 on day 49 after EAEnp induction. Treg depletion at days 18 and 19 resulted in the most severe EAE with an average peak clinical score of 2.4 on day 38 after EAEnp induction. Interestingly, Treg-cell depletion as late as days 33 and 34 still triggered severe EAE with an average peak clinical score of 1.8 on day 57 after EAEnp induction (Fig. 2A). We next sought to investigate the effects of Tregcell depletion in EAEnp on pain behaviors. On day 19 after EAEnp induction, DEREG EAEnp mice depleted of Treg cells on days 8 and 9 developed increased facial allodynia compared with EAEnp mice injected with PBS (Fig. $2 B ; p=$ 0.0005, $\left.U_{(1,16)}=49\right)$.

\section{Intraperitoneal adoptive transfer of activated Treg cells inhibits EAE progression and pain behaviors}

To assess the effects of adoptive transfer of Treg cells on EAE and associated pain, we first examined the optimal time point for peripheral Treg-cell isolation for adoptive transfer experiments. EAE mice were killed in the preclinical period (day 8), the clinical peak (day 16), or chronic phase (day 30) of EAE and flow cytometry was used to measure the proportion of Treg cells expressing a range of antiinflammatory [CD39, latency-associated peptide (LAP), and IL-10] and pro-inflammatory (IFN- $\gamma$ and IL-17) markers in the ILNs and CLNs and spleen. We observed increased numbers of Treg cells (Fig. $3 B$ ) and increased levels of CD39 (Fig. 3C,D) and LAP (Fig. $3 E, F$ ), but not IL-10, IFN- $\gamma$, and IL-17 (Fig. 3G-L), within the Treg cell population in the LNs and spleens at the later stages of disease. Therefore, day 30 after EAE induction was chosen as the optimal time point for Treg-cell isolation from the LNs and spleens of DEREG mice for adoptive transfer experiments. In addition, we confirmed the capacity of $\mathrm{GFP}^{+}$Treg cells isolated from DEREG mice to suppress CD ${ }^{+}$ $\mathrm{T}$-cell proliferation using an in vitro flow-cytometry-based suppression assay (data not shown). Because in vitro activated FoxP3 ${ }^{+}$Treg cells have been shown to be more potent than freshly isolated FoxP3 ${ }^{+}$Treg cells (Xia et al., 2015), we next examined the effects of in vitro CD3/CD28 and IL-2 activation on Treg-cell proliferation and expression of key pro-inflammatory and anti-inflammatory markers. $\mathrm{GFP}^{+}$Treg cells were isolated from pooled LNs and spleen samples obtained from DEREG EAE mice at day 30 after induction and activated in vitro. Seven days of in vitro activation increased Treg-cell numbers by $\sim 4$-fold (Fig. $\left.4 A ; p=0.0012, t_{(5)}=6.607\right)$ and flow cytometric analysis revealed that activation not only increased the expression of the anti-inflammatory markers CD39 $\left(p<0.0001, t_{(1,4)}=43.58\right)$, $\operatorname{LAP}\left(p=0.0003, t_{(1,4)}=12.71\right), \mathrm{IL}-10\left(p=0.013, t_{(1,4)}=4.307\right)$, and $\mathrm{p} 35 / \mathrm{EBI} 3$ (IL-35; $p=0.0003, t_{(1,4)}=11.52$ ), but also increased expression of the pro-inflammatory markers IFN- $\gamma(p=$ 
A
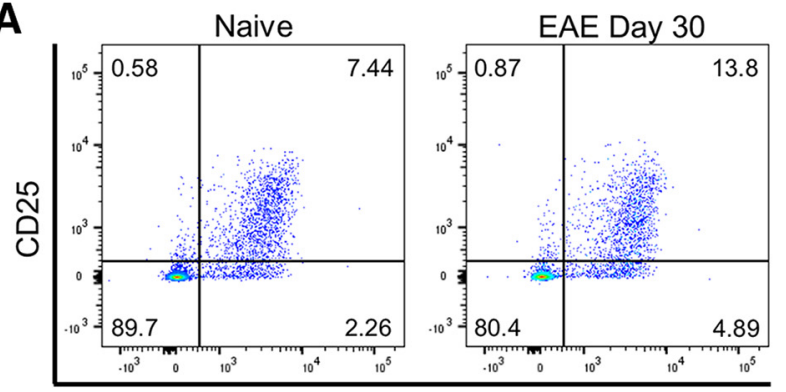

FoxP3

C

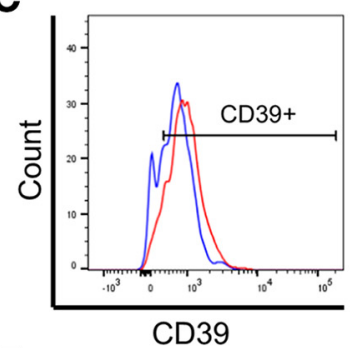

E

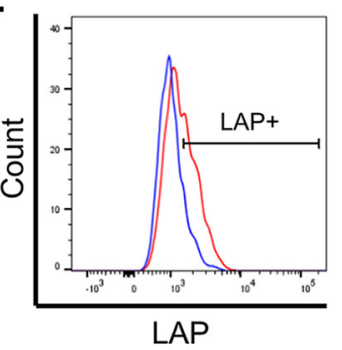

G

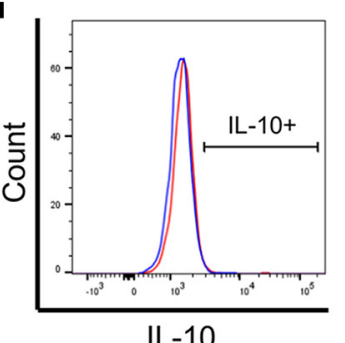

I

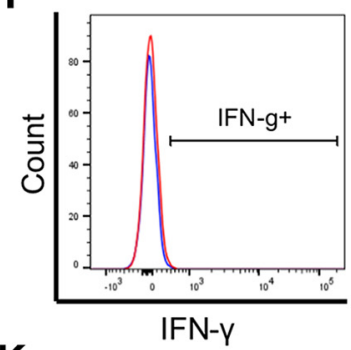

K

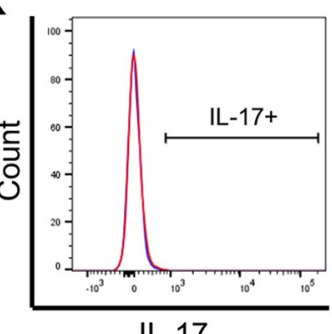

B

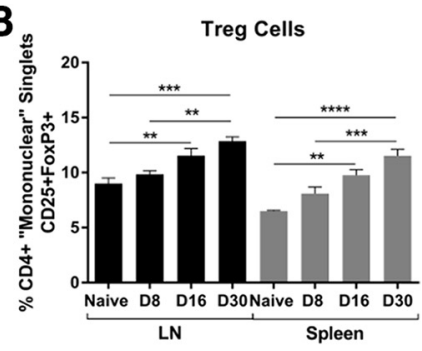

D

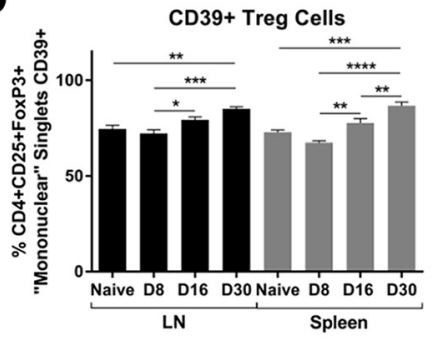

F

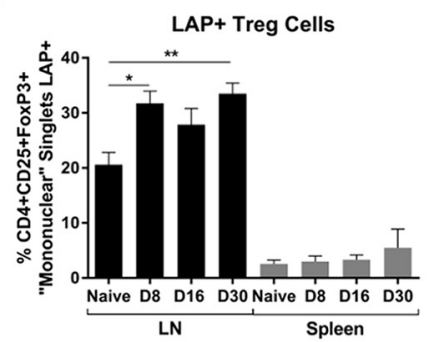

H

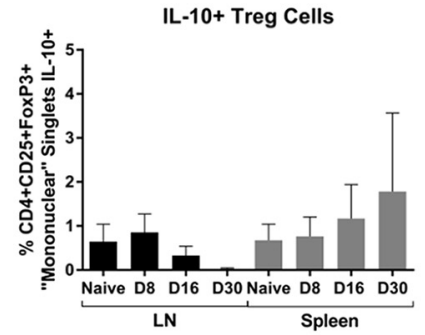

J

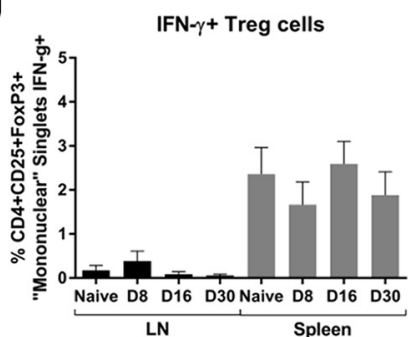

L

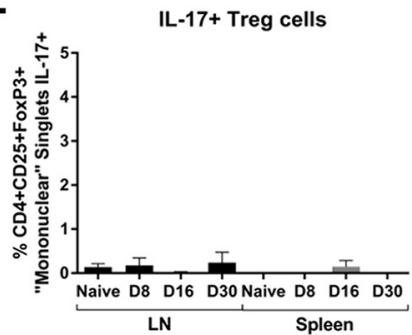

Figure 3. Peripheral Treg-cell phenotyping over the course of chronic EAE. Shown is an increased number of Treg cells expressing anti-inflammatory markers during the chronic phase of EAE. Using flow cytometry, mononuclear cells were first gated, followed by singlets (as in Fig. $1 B, C$ ) and $C D 4^{+}$cells. $A$, Representative dot plots showing $\mathrm{CD} 25^{+}$FoxP3 ${ }^{+}$(Figure legend continues.) 
$\left.0.012, t_{(1,4)}=4.356\right)$ and IL-17 $\left(p=0.0002, t_{(1,4)}=13.1\right)$, within the $\mathrm{GFP}^{+}$Treg-cell population (Fig. $4 B-N$ ).

Adoptive transfer of Treg cells by systemic injection has been previously shown to reduce EAE severity (Zhang et al., 2004; McGeachy et al., 2005); however, the effects of adoptive transfer of activated Treg cells on pain behaviors in EAE are not known. Here, Treg cells were injected $1 \mathrm{~d}$ before EAE induction to test the suppressive activity of activated Treg cells in vivo because systemic injection at the time of EAE induction allows for an assessment of peripheral suppression of EAE before the establishment of central clinical disease. Activated Treg cells delivered intraperitoneally $1 \mathrm{~d}$ before EAE induction resulted in long-term inhibition of disease progression (Fig. 5A) without a change in body weight (Fig. 5B). Both stimulus-evoked pain (facial allodynia) and spontaneous pain (facial grimacing) were assessed, as described previously (Duffy et al., 2016). Facial allodynia was reduced in EAE mice injected with Treg cells compared with EAE mice injected with saline on days $22\left(p=0.002, H_{(2,21)}=34.42\right)$ and $29\left(p=0.047, H_{(2,21)}=22.9\right)$ after EAE induction (Fig. $\left.5 C\right)$. Facial grimacing was also decreased in EAE mice injected with Treg cells compared with EAE mice injected with saline on day 20 after EAE induction (Fig. $5 D ; p=0.0402, F_{(2,21)}=6.546$ ).

We then used flow cytometry to look for the presence of GFP ${ }^{+}$ Treg cells in central tissues and assess the composition of the CNS inflammatory infiltrate in EAE mice injected with Treg cells compared with EAE mice injected with saline on day 32 after EAE induction. LAP expression was increased in the spinal cords of EAE mice injected with Treg cells compared with EAE mice injected with saline (Fig. $5 E, F ; p=0.014, t_{(1,13)}=2.834$ ); however, no further changes were seen in the inflammatory infiltrate and no $\mathrm{GFP}^{+}$cells were identified $33 \mathrm{~d}$ after Treg-cell injection (data not shown).

\section{Intrathecal adoptive transfer of activated $\mathrm{GFP}^{+}$Treg cells reduces facial allodynia without affecting EAE progression} Because adoptive transfer of Treg cells by systemic injection may affect EAE progression and associated pain through actions in the periphery, we next aimed to investigate the therapeutic potential of central injection of Treg cells on clinical EAE and associated pain behaviors. Treg cells were injected intrathecally $11 \mathrm{~d}$ after EAE induction because this coincided with the onset of clinical

\footnotetext{
$\leftarrow$

(Figure legend continued.) staining out of total $\mathrm{CD}^{+}{ }^{+}$mononuclear singlets in naive and EAE mice at day 30 after induction. $\boldsymbol{B}$, Bar graph showing an increase in Treg cells in the LNs and spleens at day 16 and 30 after EAE induction compared with naive animals. Treg cells were also increased in the LNs and spleens at day 30 compared with day 8 after EAE induction. C, Representative histogram showing $\mathrm{CD} 39^{+}$staining out of total Treg cells in naive and EAE mice at day 30 after induction. D, Bar graph showing an increase in $\mathrm{CD}_{3}{ }^{+}$Treg cells in the LNs and spleens at day 30 after EAE induction compared with naive animals. $\mathrm{CD}{ }^{+}{ }^{+}$Treg cells were also increased in the LNs and spleens at day 16 and 30 compared with day 8 after EAE induction and at day 30 after EAE induction in the spleens compared with naive animals. $\boldsymbol{E}$, Representative histogram showing $\mathrm{LAP}^{+}$staining out of total Treg cells in naive and EAE mice at day 30 after induction. $\boldsymbol{F}$, Bar graph showing an increase in LAP ${ }^{+}$Treg cells in the LNs at day 8 and 30 after EAE induction compared with naive animals. $\boldsymbol{G}$, Representative histogram showing $\mathrm{IL}-10^{+}$ staining out of total Treg cells in naive and EAE mice at day 30 after induction. $\boldsymbol{H}$, Bar graph showing no change in $\mathrm{IL}-10^{+}$Treg cells in the LNs or spleens over the course of chronic EAE. I, Representative histogram showing IFN- $\gamma^{+}$staining out of total Treg cells in naive and EAE mice at day 30 after induction. J, Bar graph showing no change in IFN- $\gamma^{+}$Treg cells in the LNs or spleens over the course of chronic EAE. $\boldsymbol{K}$, Representative histogram showing IL-17 ${ }^{+}$staining out of total Treg cells in naive and EAE mice at day 30 after induction. $L$, Bar graph showing no change in IL- $17^{+}$Treg cells in the LNs or spleens over the course of chronic EAE. ${ }^{*} p<0.05$, ${ }^{* *} p<0.01,{ }^{* * *} p<0.001,{ }^{* * * *} p<0.0001$, one-way ANOVA followed by Tukey's post hoc test, $n=5$. Data are expressed as mean \pm SEM.
}

EAE and the development of central neuroinflammation. Little is known about the fate of Treg cells following intrathecal injection, which prompted us to use flow cytometry to assess the presence of $\mathrm{GFP}^{+}$Treg cells in lymphatic and nervous tissue $48 \mathrm{~h}$ after injection. $\mathrm{GFP}^{+}$cells were observed in the brain of Treg-cellinjected mice (Fig. 6; $p=0.011, t_{(1,8)}=3.285$ ), but were absent in the ILNs and CLNs, spinal cord, and DRG.

Treg cells delivered intrathecally at the onset of EAE (day 11 after EAE induction) had no effect on disease progression (Fig. $7 A$ ) or body weight (Fig. 7B). Following established facial allodynia in EAE mice on day 10, intrathecal Treg-cell injection was found to reduce facial allodynia on days $16\left(p=0.001, H_{(2,44)}=\right.$ $34)$ and $23\left(p=0.012, H_{(2,44)}=35.1\right)$ after EAE induction. This effect lost statistical significance by day 31 after EAE induction (Fig. 7C). No significant effect on facial grimacing was seen in EAE mice injected with Treg cells compared with EAE mice injected with saline (Fig. 7D). Flow cytometry was performed on the spinal cords at the end of the $32 \mathrm{~d}$ monitoring period and no changes in the inflammatory infiltrate or numbers of $\mathrm{GFP}^{+}$Treg cells were seen in the spinal cord following intrathecal injection of Treg cells (data not shown).

\section{Intrathecal adoptive transfer of activated Treg cells reduces astrocyte immunoreactivity and increases myelination in the trigeminal pathway of EAE mice}

Because intrathecal adoptive transfer of Treg cells decreased facial allodynia, mice were killed at the end of the $32 \mathrm{~d}$ monitoring period for analysis of the trigeminal nuclei by immunohistochemistry for GFAP (astrocyte marker), IBA-1 (macrophage/microglial marker), and 4C12 (infiltrating monocytes). GFAP immunoreactivity (Fig. $8 A-C, J$ ) and IBA-1 immunoreactivity (Fig. $8 D-F, K$ ) were significantly increased in EAE mice relative to controls. However, GFAP staining (Fig. 8A-C) revealed a decrease in EAE mice injected with Treg cells compared with EAE mice injected with saline (Fig. 8J; $p<0.0001, F_{(2,11)}=32.38$ ), whereas IBA-1 staining (Fig. $8 D-F$ ) showed no change (Fig. $8 K$ ). Analysis of $4 \mathrm{C} 12$ staining (Fig. 8G-I) showed a trend for decreased cell numbers in EAE mice injected with Treg cells compared with EAE mice injected with saline, but this was not statistically significant (Fig. $8 L ; p=0.14$ ).

Given that Treg cells have recently been shown to promote myelin regeneration in the CNS (Dombrowski et al., 2017), we investigated whether the inhibition of allodynia that we saw in Treg-cell-injected mice is accompanied by reduced demyelination in nociceptive pathways. Myelin was assessed using BlackGold II staining (Fig. 9A-C) of the spinal trigeminal tract (Fig. $9 D$ ). This revealed a decrease in myelination in EAE mice injected with saline compared with control mice injected with saline ( $p=$ 0.0002 ) and an increase in myelination in EAE mice injected with Treg cells compared with EAE mice injected with saline (Fig. 9E; $\left.p=0.0088, F_{(2,12)}=18.51\right)$.

\section{Intrathecal IL-35 therapy reduces clinical disease and pain behaviors in mice with EAE}

To investigate whether levels of IL-35 are altered at the clinical peak of EAE (day 16 after induction) in the CNS, an IL-35 ELISA was performed. IL-35 levels were decreased in the spinal cord of EAE mice compared with control mice $\left(p=0.0008, F_{(1,12)}=\right.$ 105.4), with no change seen in the brain (Fig. 10A). Considering this, we tested the effects of central delivery of IL-35 by intrathecal injection on EAE progression and pain behaviors. Following onset of clinical disease in EAE mice (day 11), intrathecal IL-35 or 
A

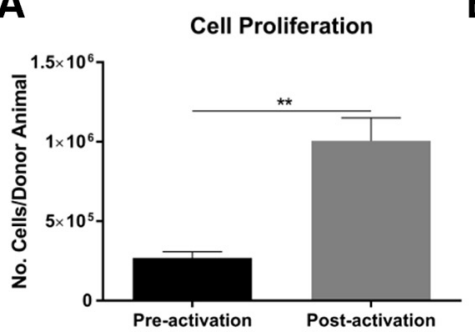

E

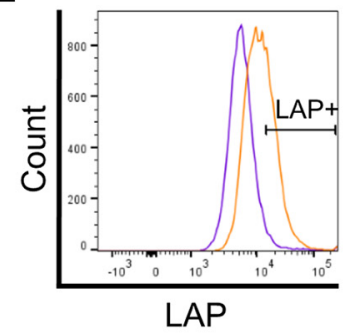

B

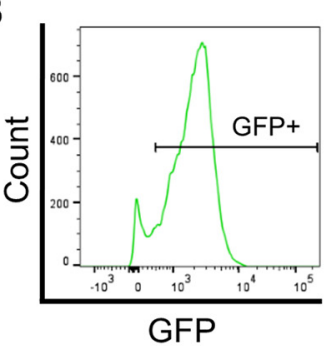

F

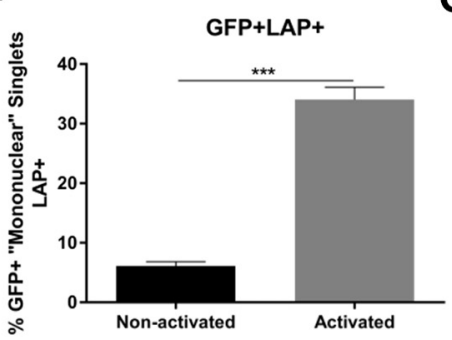

C

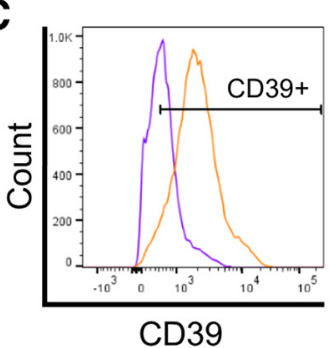

G

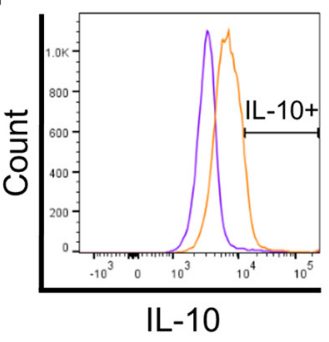

D

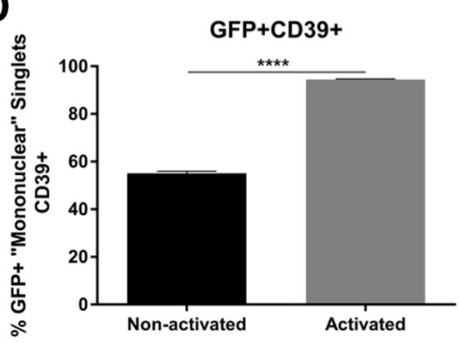

H

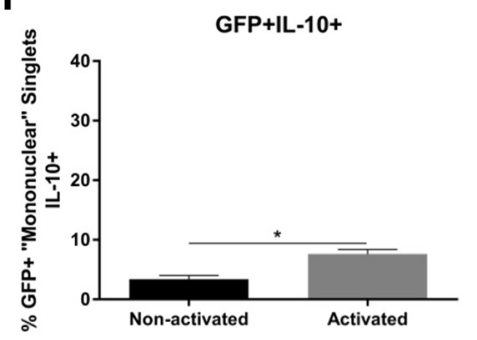

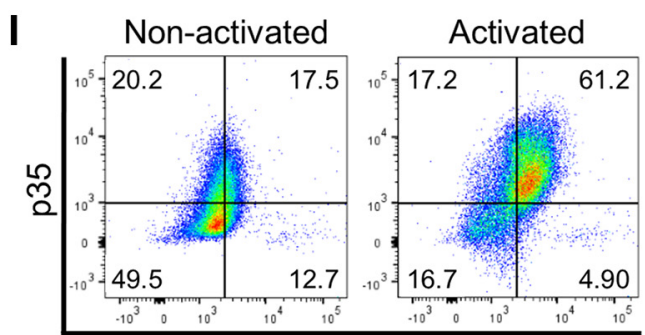

$\mathrm{EBI} 3$
J

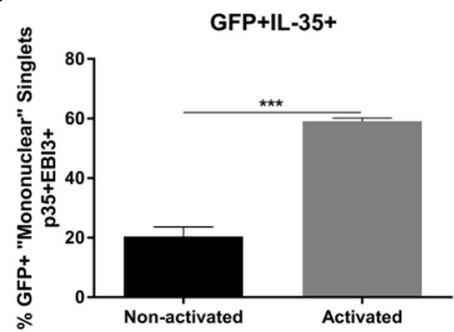

K

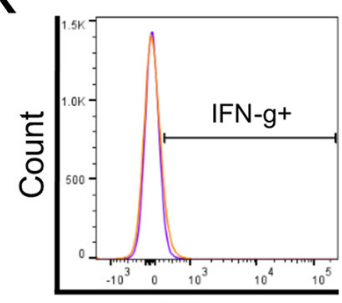

IFN-Y
L

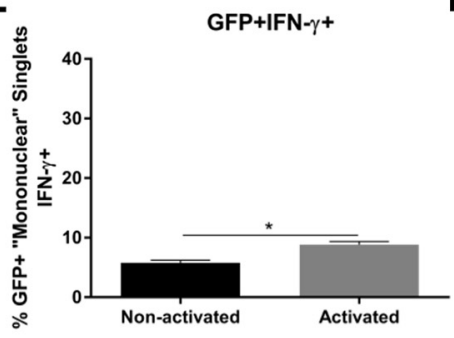

M

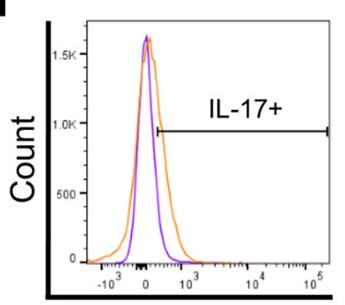

IL-17
N

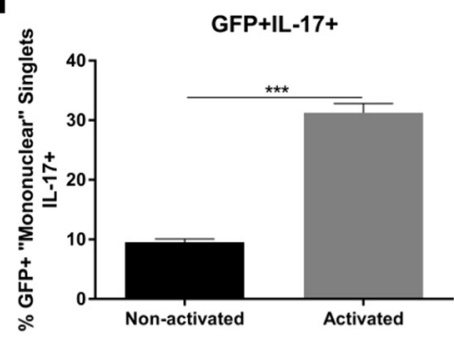

Figure 4. In vitro activation of GFP ${ }^{+}$Treg cells results in cell proliferation and increased cytokine expression. In vitro activation of GFP ${ }^{+}$Treg cells derived from DEREG mice at day 30 after EAE induction was performed with $\mathrm{CD} 3 / \mathrm{CD} 28+\mathrm{IL}-2$. A, Bar graph showing increased numbers of $\mathrm{GFP}^{+}$Treg cells following the $7 \mathrm{~d}$ activation period compared with numbers of GFP ${ }^{+}$Treg cells preactivation per donor animal ( $n=3$, paired $t$ test). For flow cytometric analysis of Treg cells following the $7 \mathrm{~d}$ activation, mononuclear cells were first gated, followed by singlets (as in Fig. $1 B, C$ ). $\mathrm{GFP}^{+}$cells were then gated $(\boldsymbol{B})$, followed by analysis of $\mathrm{CD} 39(\boldsymbol{C}), \mathrm{LAP}(\boldsymbol{E}), \mathrm{IL}-10(\boldsymbol{G}), \mathrm{IL}-35\left(\mathrm{p} 35^{+}\right.$EBI3 $\left.{ }^{+}\right)(\boldsymbol{I}), \mathrm{IFN}-\gamma(\boldsymbol{K})$, and IL-17 $(\boldsymbol{M})$ expression in nonactivated versus activated GFP ${ }^{+}$Treg cells. $\mathrm{GFP}^{+} \mathrm{CD}^{2} 9^{+}(\boldsymbol{D}), \mathrm{GFP}^{+} \mathrm{LAP}^{+}(\boldsymbol{F}), \mathrm{GFP}^{+} \mathrm{IL}-10^{+}(\boldsymbol{H}), \mathrm{GFP}^{+} \mathrm{IL}-35^{+}(\boldsymbol{J}), \mathrm{GFP}^{+} \mathrm{IFN}-\gamma^{+}(\mathbf{L})$, and GFP ${ }^{+} \mathrm{IL}-17^{+}(\boldsymbol{N})$ Treg cells were all increased following $7 \mathrm{~d}$ activation compared with nonactivated cells $\left(n=3\right.$, unpaired Student's $t$ test). ${ }^{*} p<0.05$, ${ }^{* *} p<0.01$, ${ }^{* *} p<0.001$, ${ }^{* * * *} p<0.0001$. Data are expressed as mean \pm SEM.

saline injections were given on days 11, 13, and 15 after induction. Intrathecal IL-35 therapy in EAE mice resulted in a modest decrease in clinical disease on days $19(p=0.0039)$ and $20(p=$ $\left.0.0428, F_{(2,29)}=84.72\right)$ of the $20 \mathrm{~d}$ monitoring period (Fig. $\left.10 B\right)$. No change in percentage body weight loss was seen between EAE mice receiving intrathecal IL-35 therapy compared with EAE mice injected with saline (Fig. 10C). Facial allodynia was established in EAE mice on day 9 after induction and was decreased in EAE mice following IL-35 therapy compared with EAE mice injected with saline on days $12\left(p=0.0498, H_{(2,29)}=28.85\right), 14$ $\left(p=0.032, H_{(2,29)}=29.95\right)$, and $16\left(p=0.032, H_{(2,29)}=21.17\right)$ after induction; that is, $1 \mathrm{~d}$ after each IL-35 injection. This effect was lost by day 19 after induction, suggesting that the effect of intrathecal IL-35 therapy on facial allodynia is transient (Fig. $10 D)$. The MGS revealed a decrease in spontaneous pain in EAE mice receiving intrathecal IL-35 therapy compared with EAE mice injected with saline on day 19 after induction (Fig. 10E; $p=$ $\left.0.043, F_{(2,29)}=9.316\right)$.

\section{Intrathecal IL-35 therapy increases IL-10 expression in T and} $B$ cells within the CNS

Given that the effects of intrathecal IL-35 therapy on facial allodynia appeared to be transient, we next analyzed the CNS for a range of $\mathrm{T}$ - and $\mathrm{B}$-cell subtypes $1 \mathrm{~d}$ after the final intrathecal injection (day 16 after induction) using flow cytometry. The spinal cords and brainstems (location of the trigeminal nuclei) were 
A

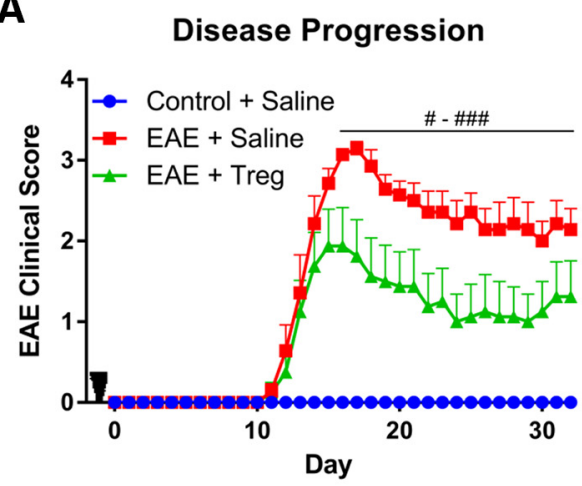

C

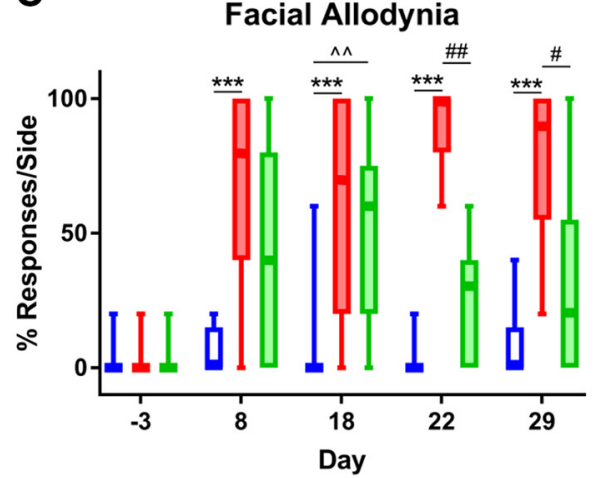

E

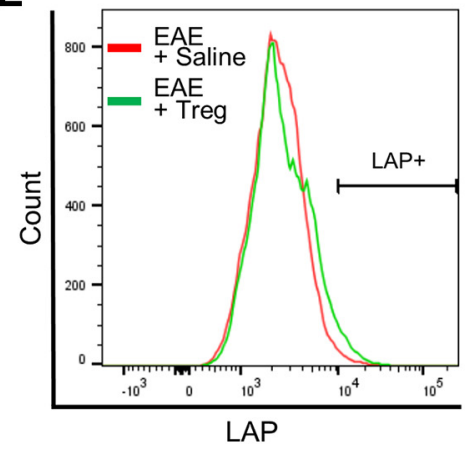

B

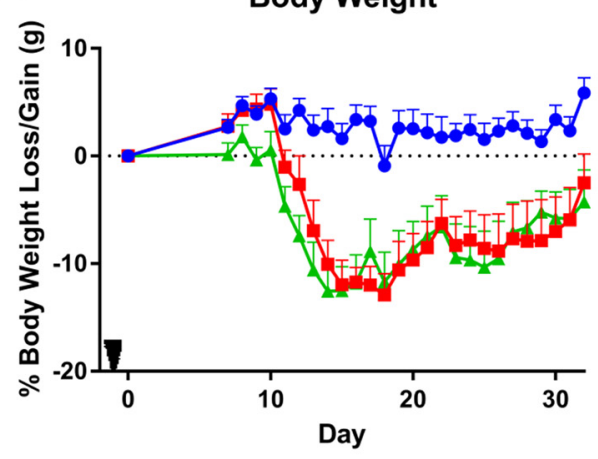

D

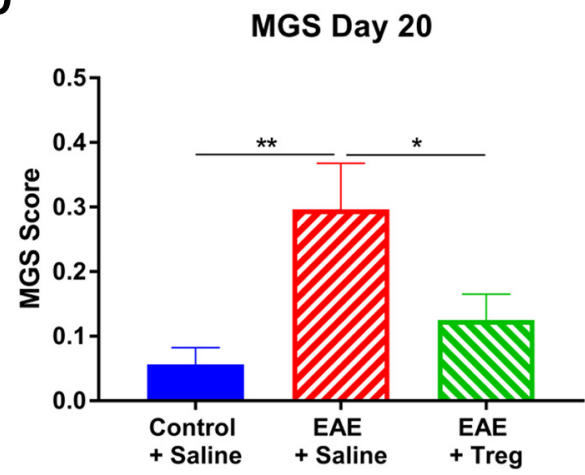

$\mathbf{F}$

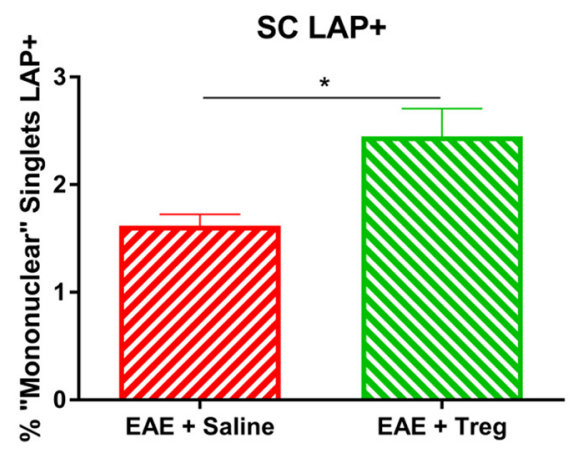

Figure 5. EAE disease progression, pain behaviors, and flow cytometry of the spinal cord following intraperitoneal adoptive transfer of activated GFP ${ }^{+}$Treg cells. $A$, EAE disease progression following intraperitoneal adoptive transfer of Treg cells. A reduction in EAE clinical scores was seen from days 16 to 32 after induction in EAE mice injected with intraperitoneal Treg cells compared with EAE mice injected with intraperitoneal saline $(n=7-8)$. \#p $<0.05$, \#\#p $<0.01$ and \#\#\#p $<0.001$, repeated-measures two-way ANOVA with Tukey's posthoc test. $\boldsymbol{B}$, Percentage body weight loss/gain recorded following intraperitoneal adoptive transfer of Treg cells. Black arrowheads represent time points at which Treg cells or saline were injected intraperitoneally (1 d before EAE induction) ( $n=7-8)$. C, Facial allodynia observed over the course of chronic EAE. On days 22 and 29 after induction, a decrease in facial allodynia was observed in EAE mice injected intraperitoneally with Treg cells compared with EAE mice injected intraperitoneally with saline $(n=7-8){ }^{* * *} p<0.001$ signifies a significant difference between control and EAE + saline groups, $\wedge \wedge p<0.01$ signifies a significant difference between control and EAE + Treg groups, and \#p $<0.05$ and \#\# $p<0.01$ signify a significant difference between EAE + saline and EAE + Treg groups; Kruskal-Wallis test with Dunn's post hoc test and Holm-Bonferroni correction for multiple comparisons. D, Facial grimacing observed on day 20 after induction. A decreased MGS score was seen in EAE mice injected intraperitoneally with Treg cells compared with EAE mice injected intraperitoneally with saline. An increased MGS score was also seen in EAE mice injected intraperitoneally with saline compared with control mice $(n=7-8) .{ }^{*} p<0.05,{ }^{* *} p<0.01$, one-way ANOVA with Tukey's post hoc test. E, Representative histogram showing LAP ${ }^{+}$staining in the SC of EAE mice injected intraperitoneally with saline and EAE mice injected intraperitoneally with Treg cells at day 32 after induction. $\boldsymbol{F}$, Bar graph showing increased LAP expression in the SC of EAE mice injected intraperitoneally with Treg cells compared with EAE mice injected intraperitoneally with saline $(n=7-8)$. ${ }^{*} p<0.05$, unpaired Student's $t$ test. EAE clinical scores, body weight, MGS, and flow cytometry data are expressed as mean \pm SEM, whereas facial allodynia data are expressed as box-and-whisker plots in which box limits show the first and third quartile, the center line is the median, and the whiskers represent the minimum and maximum values.

then analyzed for the expression of the pro- and antiinflammatory markers IFN- $\gamma$, IL-17, IL-4, LAP, IL-10, and IL-35 in $\mathrm{CD} 4^{+}$, Treg, $\mathrm{CD} 8{ }^{+}$, and $\mathrm{CD} 19^{+}$cells. Following selection of $\mathrm{CD}^{+}, \mathrm{CD} 8^{+}$, or $\mathrm{CD} 19^{+}$cells (Fig. $11 A, D, G$, respectively), IL-10 levels were compared between IL-35-treated EAE mice and saline-injected EAE mice in the spinal cord and brainstem (Fig. $11 B, E, H)$. An increase in $\mathrm{CD} 4{ }^{+} \mathrm{IL}-10^{+}$cells was observed in the spinal cord $\left(p=0.031, t_{(1,11)}=2.481\right)$ and brainstem $(p=0.036$, $\left.t_{(1,11)}=2.394\right)$ of EAE mice receiving IL-35 therapy (Fig. 11C). An increase in CD8 ${ }^{+} \mathrm{IL}-10^{+}$cells was also observed in the brainstem of EAE mice receiving IL-35 therapy (Fig. 11F; $p=0.0246$, $\left.t_{(1,11)}=2.601\right)$. In addition, $\mathrm{CD} 19^{+} \mathrm{IL}-10^{+}$cells were increased in the spinal cord of EAE mice receiving IL-35 therapy (Fig. 11I; $\left.p=0.0253, t_{(1,11)}=2.587\right)$. No changes were seen between IL-35and saline-treated EAE mice in any of the other cell subtypes analyzed within the spinal cord or brainstem (data not shown). 
A

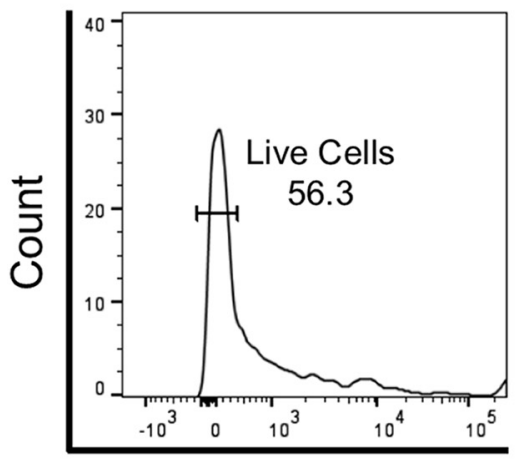

Zombie UV
B

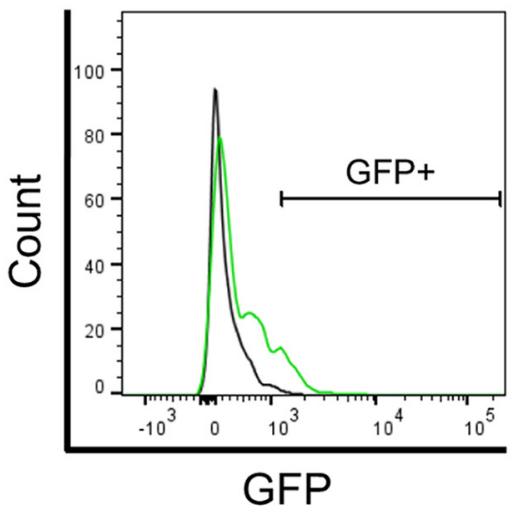

C

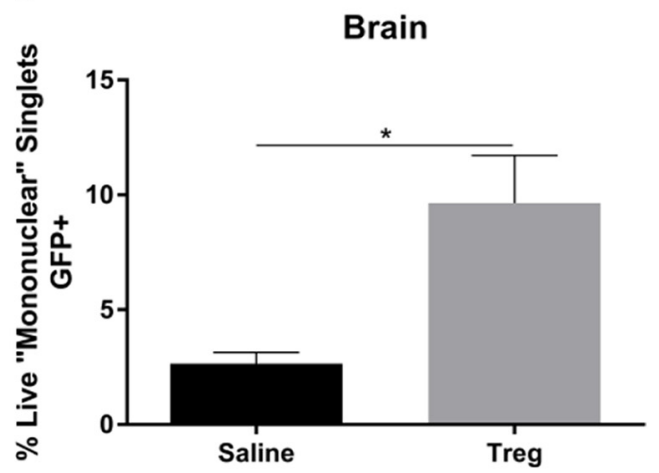

Figure 6. $\mathrm{GFP}^{+}$Treg cells accumulate in the brains of mice $48 \mathrm{~h}$ following intrathecal adoptive transfer. Flow cytometry was performed $48 \mathrm{~h}$ following intrathecal injection of activated GFP ${ }^{+}$ Treg cells in naive mice. Mononuclear cells were first gated, followed by singlets (as in Fig. $1 B, C$, and live cells ( $\boldsymbol{A}$ ). $\boldsymbol{B}$, Representative histogram showing GFP staining in the brain of mice injected intrathecally with saline versus mice injected intrathecally with Treg cells. $C$, Bar graph showing increased levels of GFP ${ }^{+}$staining in the brain of mice injected intrathecally with Treg cells compared with mice injected intrathecally with saline. ${ }^{*} p<0.05$, unpaired Student's $t$ test, $n=5$. Data are expressed as mean \pm SEM.

A

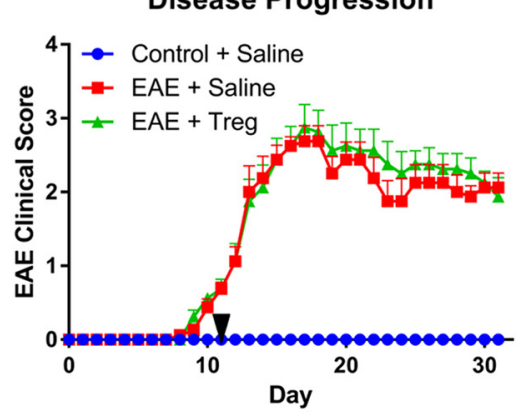

C

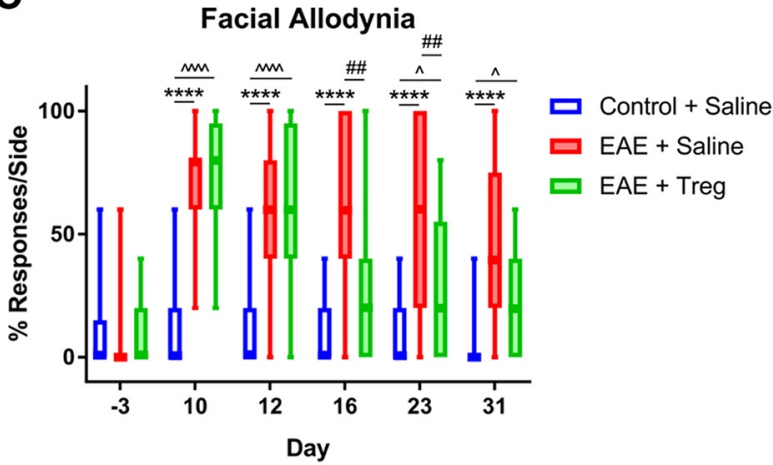

B

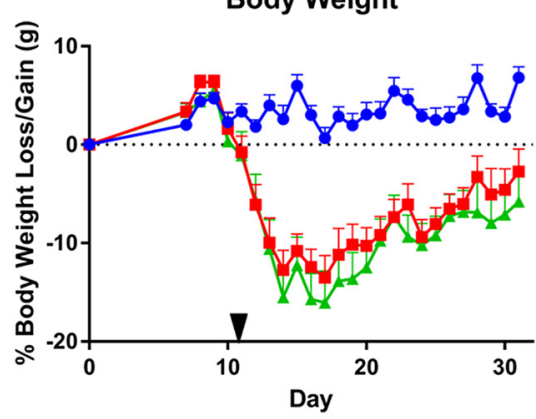

D

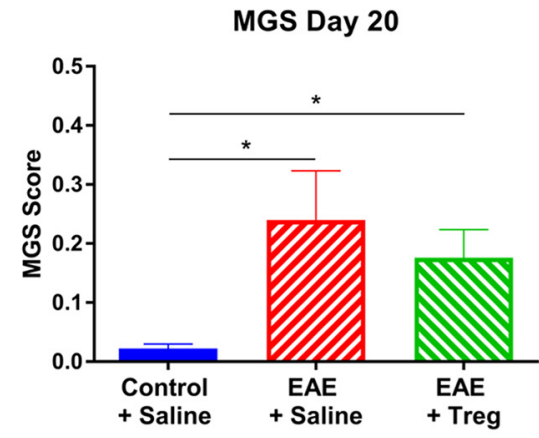

Figure 7. EAE disease progression and pain behaviors following intrathecal adoptive transfer of activated GFP ${ }^{+}$Treg cells. A, EAE disease progression following intrathecal adoptive transfer of Treg cells. $\boldsymbol{B}$, Percentage body weight loss/gain recorded following intrathecal adoptive transfer of Treg cells. Black arrowheads represent time points at which Treg cells or saline were injected intrathecally (disease onset; day 11 after EAE induction) $(n=8)$. C, Facial allodynia observed over the course of chronic EAE. On days 16 and 23 after induction, a decrease in facial allodynia was observed in EAE mice injected intrathecally with Treg cells compared with EAE mice injected intrathecally with saline $(n=15-16) .{ }^{* * * *} p<0.0001$ signifies a significant difference between control and EAE + saline groups, $\wedge \wedge p<0.01$ and $\wedge \wedge \wedge \wedge p<0.0001$ signify a significant difference between control and EAE + Treg groups, and \#\# $p<0.01$ signifies a significant difference between $\mathrm{EAE}+$ saline and EAE + Treg groups, Kruskal-Wallis test with Dunn's post hoc test and Holm-Bonferroni correction for multiple comparisons. D, An increased MGS score was seen in EAE mice injected intrathecally with saline and EAE mice injected intrathecally with Treg cells compared with control mice $(n=8)$. ${ }^{*} p<0.05$, one-way ANOVA with Tukey's post hoc test. EAE clinical scores, body weight, and MGS data are expressed as mean \pm SEM, whereas facial allodynia data are expressed as box-and-whisker plots in which box limits show the first and third quartile, the center line is the median, and the whiskers represent the minimum and maximum values.

Intrathecal IL-35 therapy reduces monocyte infiltration and macrophage/microglial activation and increases myelination in the trigeminal pathway of EAE mice

At the end of the $20 \mathrm{~d}$ monitoring period, mice were killed for analysis of the trigeminal nuclei by immunohistochemistry. GFAP staining (astrocyte marker; Fig. $12 A-C$ ) revealed an in- crease in EAE mice injected intrathecally with saline compared with control mice $\left(p=0.0061, F_{(2,12)}=7.386\right)$, with no significant change (despite a decreasing trend) in IL-35-treated mice compared with saline-treated EAE mice (Fig. 12M). IBA-1 staining (macrophage/microglial marker; Fig. $12 D-F$ ) was increased in EAE mice receiving intrathecal IL-35 $(p=0.031)$ and saline 

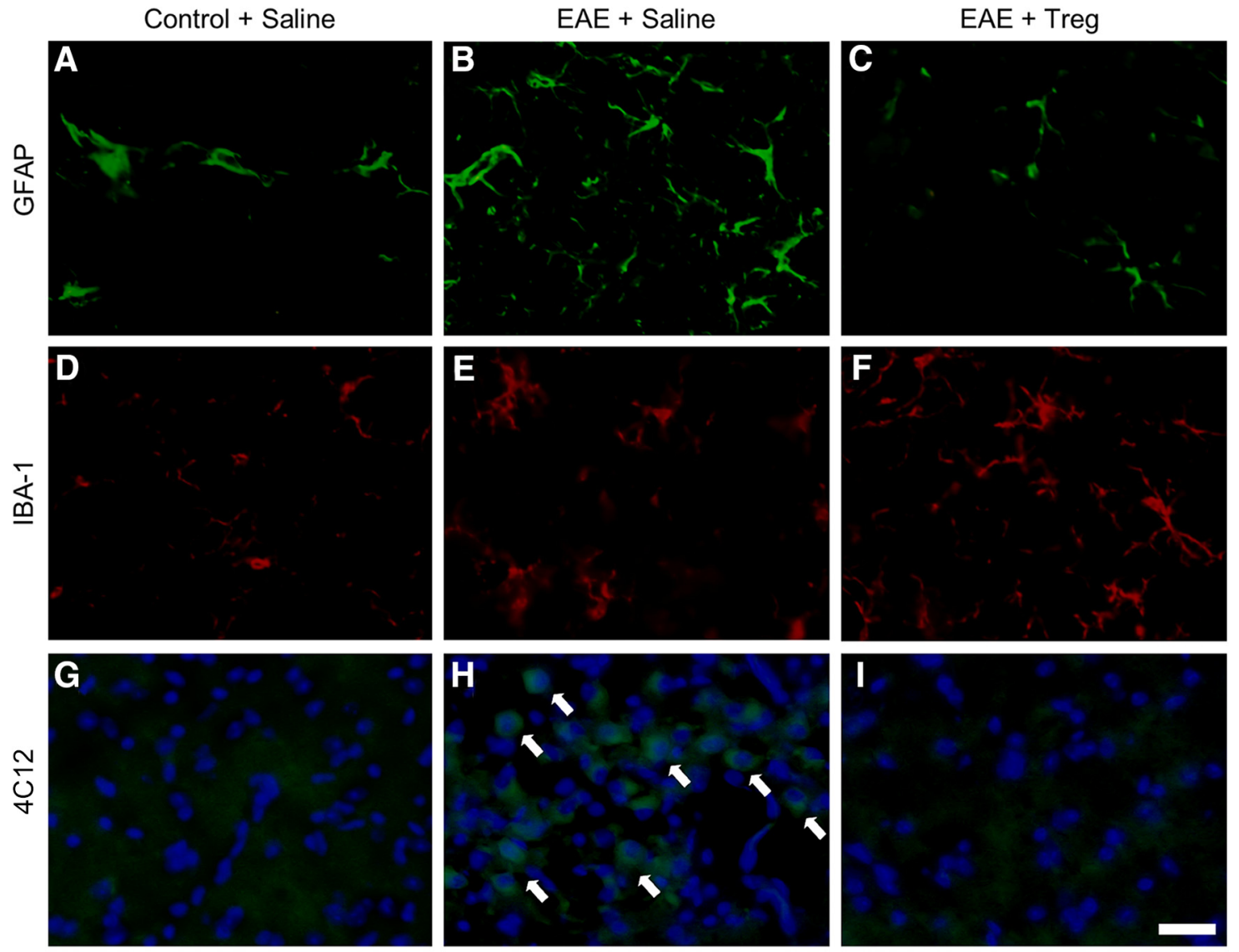

$\mathbf{J}$

GFAP Trigeminal Nuclei

K

IBA-1 Trigeminal Nuclei
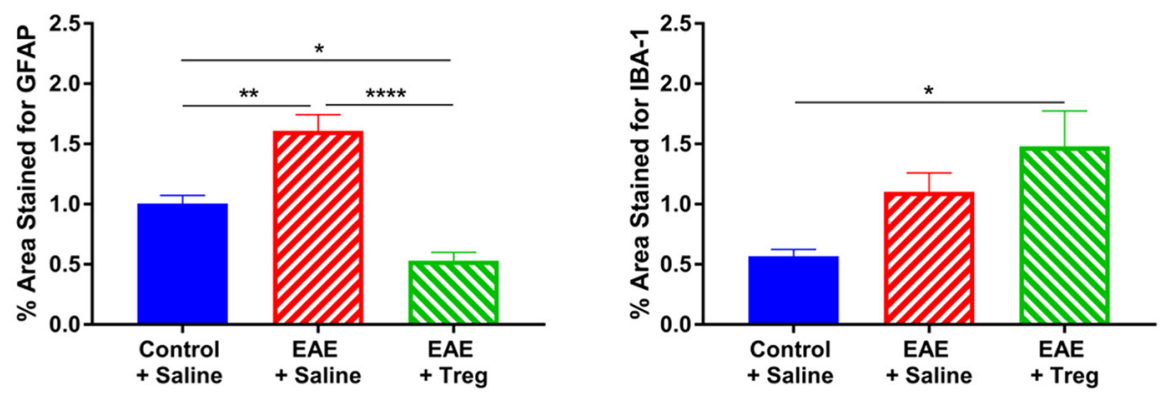

$\mathbf{L}$

4C12 Trigeminal Nuclei

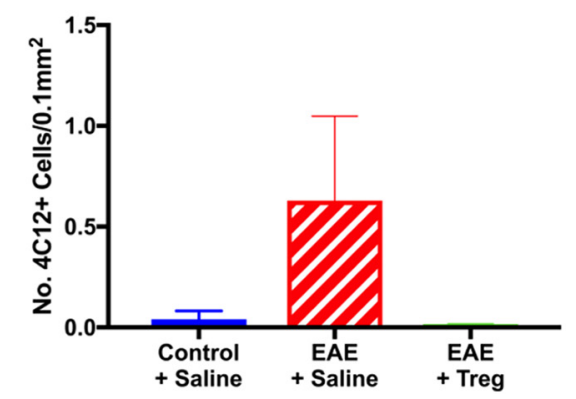

Figure 8. Changes in astrocyte and macrophage/microglia expression following intrathecal adoptive transfer of activated GFP ${ }^{+}$Treg cells in EAE. Immunohistochemistry was performed on the trigeminal nuclei of mice injected intrathecally with activated GFP ${ }^{+}$Treg cells on day 11 and assessed on day 32 after induction. Representative images of GFAP (activated astrocytes; $\boldsymbol{A}-\boldsymbol{C}$ ), IBA-1 (macrophages/microglia; $\boldsymbol{D}-\boldsymbol{F}$ ), and $4 \mathrm{C} 12$ (infiltrating monocytes; $\mathbf{G}-\boldsymbol{I}$ ) staining performed on the trigeminal nuclei in control mice injected intrathecally with saline, EAE mice injected intrathecally with saline, and EAE mice injected intrathecally with Treg cells. Scale bar, $25 \mu \mathrm{m}$.J, Bar graph showing decreased levels of GFAP immunostaining in EAE mice injected intrathecally with Treg cells compared with EAE mice injected intrathecally with saline. Levels of GFAP staining were also increased in EAE mice injected intrathecally with saline compared with control mice injected intrathecally with saline and decreased in EAE mice injected intrathecally with Treg cells compared with control mice injected intrathecally with saline. $\boldsymbol{K}$, Bar graph showing increased IBA-1 immunostaining in EAE mice injected intrathecally with Treg cells compared with control mice injected intrathecally with saline. L, Bar graph showing no change in $4 C 12^{+}$cell numbers (Figure legend continues.) 
$(p<0.0001)$ compared with control mice, but decreased in EAE mice receiving intrathecal IL-35 therapy compared with EAE mice injected with saline (Fig. 12N; $\left.p=0.0014, F_{(2,12)}=29.53\right)$. Due to the reduction in IBA-1 staining seen with IL-35 therapy and because IBA-1 staining is unable to differentiate macrophages and microglia, further staining for P2ry 12 (homeostatic microglia marker; Fig. $12 \mathrm{G}-\mathrm{I}$ ) and $4 \mathrm{C} 12$ (infiltrating monocytes marker; Fig. 12J-L) was conducted. P2ry12 staining was decreased in both EAE mice receiving intrathecal IL-35 therapy $(p=0.0057)$ and EAE mice injected with saline $\left(p=0.0021, F_{(2,12)}=11.75\right)$ compared with control mice (Fig. 12O), but no change was seen between EAE groups. However, the number of $4 \mathrm{C}_{12}{ }^{+}$ cells was significantly higher in EAE mice injected intrathecally with saline compared with both control mice $(p<$ $0.0001)$ and EAE mice receiving intrathecal IL-35 therapy (Fig. 12P; $p<0.0001$, $\left.F_{(2,12)}=36.17\right)$, indicating reduced monocyte infiltration in IL-35-treated EAE mice.

Black-Gold II staining of the spinal trigeminal tract (Fig. 13A-C) revealed a decrease in myelination in EAE mice compared with control mice. However, myelination was increased in EAE mice injected with IL-35 compared with EAE mice injected with saline (Fig. $13 D ; p=0.0081, F_{(2,12)}=22.99$ ).

\section{Intrathecal IL-35 therapy in Treg-depleted mice has no effect on EAEnp disease progression or pain behaviors}

Next, we investigated whether the effect of IL-35 on disease progression and facial allodynia is mediated through Treg cells. To this end, we tested whether Treg-cell depletion by DTx injections in DEREG mice with EAEnp abrogates the effects of IL-35 treatment. Treg-cell depletion in DEREG mice triggered severe clinical EAE in both saline- and IL-35-treated mice. There was no change in clinical disease or percentage body weight loss between DEREG mice with EAEnp injected with DTx (Treg-depleted mice) and given intrathecal saline compared with those given intrathecal IL-35 (Fig. 14A, B). Facial allodynia was increased in saline-injected Treg-depleted EAEnp mice (DEREG + DTx + saline) compared with non-Treg-depleted EAEnp mice (WT + DTx + saline $)$ on days $16\left(p=0.004, H_{(2,24)}=12.24\right), 24(p=0.001$, $\left.H_{(2,24)}=17.84\right)$, and $28\left(p=0.001, H_{(2,24)}=20.01\right)$ after induction. There was also an increase in facial allodynia in IL-35injected Treg-depleted EAEnp mice (DEREG + DTx + IL-35) compared with non-Treg-depleted EAEnp mice (WT $+\mathrm{DTx}+\mathrm{sa}$ line $)$ on days $24\left(p=0.046, H_{(2,24)}=17.84\right)$ and $28(p=0.016$, $\left.H_{(2,24)}=20.01\right)$ after induction. However, no difference was seen

\section{$\leftarrow$}

(Figure legend continued.) between treatment groups, although a trend for decreased numbers of $4 \mathrm{C}^{2} 2^{+}$cells was noted in EAE mice injected intrathecally with Treg cells compared with EAE mice injected intrathecally with saline $(p=0.1362) .{ }^{*} p<0.05,{ }^{* *} p<0.01,{ }^{* * * *} p<$ 0.0001 , one-way ANOVA with Tukey's post hoc test, $n=3-5$. Data are expressed as mean \pm SEM. between Treg-depleted EAEnp mice given intrathecal saline (DEREG + DTx + saline) compared with those injected with intrathecal IL-35 (DEREG + DTx + IL-35) throughout the $30 \mathrm{~d}$ monitoring period (Fig. 14C). Facial grimacing was increased in EAEnp mice that underwent Treg-cell depletion (DEREG + DTx + saline and DEREG + DTx + IL-35) compared with non-Tregdepleted EAEnp mice (WT + DTx + saline) on day 20 after EAE induction $\left(p=0.0495\right.$ and $p=0.0353$, respectively; $F_{(2,12)}=$ 4.762). However, no change was seen following IL-35 therapy in Treg-depleted EAEnp mice (Fig. 14D).

\section{Discussion}

Treg cells and their novel cytokine IL-35 have recently been shown to play a suppressive role in EAE (McGeachy et al., 2005; Zhang et al., 2006; Korn et al., 2007; Collison et al., 2010; Matsushita et al., 2010; Koutrolos et al., 2014; Shen et al., 2014; Haller et al., 2017), but their role in EAE-associated pain is unknown. Here, using a range of behavioral, cellular, and histological techniques, we demonstrate that: (1) depletion of Treg cells induces facial allodynia in EAE mice and, conversely, adoptive transfer of activated Treg cells reduces pain behaviors independently of disease progression and increases myelination in EAE mice; (2) intrathecal IL-35 therapy reduces pain behaviors in EAE mice and is associated with changes in the inflammatory infiltrate and increased myelination; and (3) the effects of intrathecal IL-35 therapy on pain behaviors appear to be dependent on the presence of Treg cells.

Treg-cell depletion in DEREG mice has been shown to induce mortality in animals with chronic EAE (Koutrolos et al., 2014). We demonstrated that Treg-cell depletion time dependently triggers clinical EAE, which is most severe when Treg cells are depleted at time points following, but not before, EAEnp induction. In addition, we demonstrate that Treg-cell depletion in DEREG 
A

\section{Day 16 IL-35}

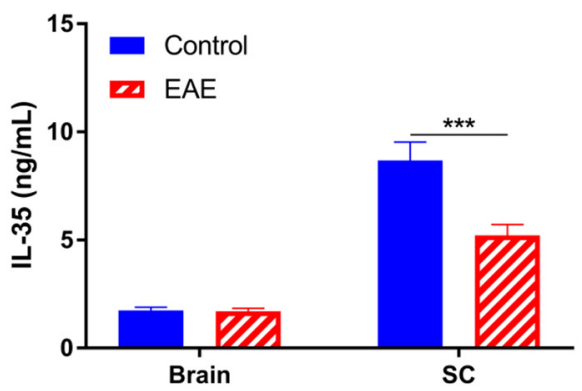

B

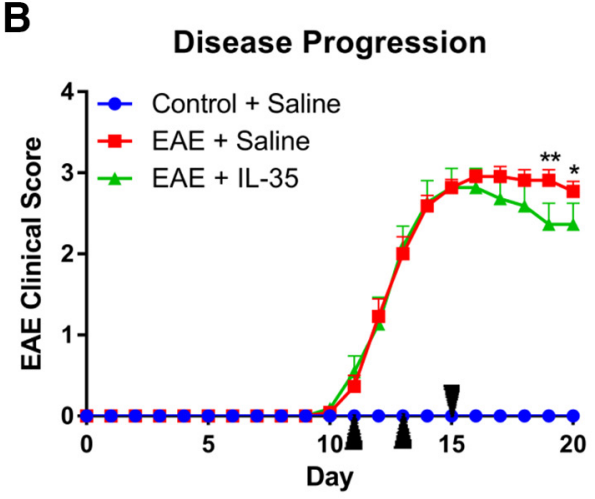

D

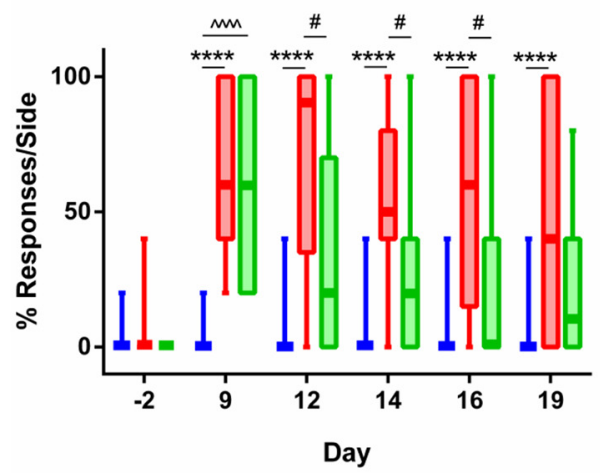

C

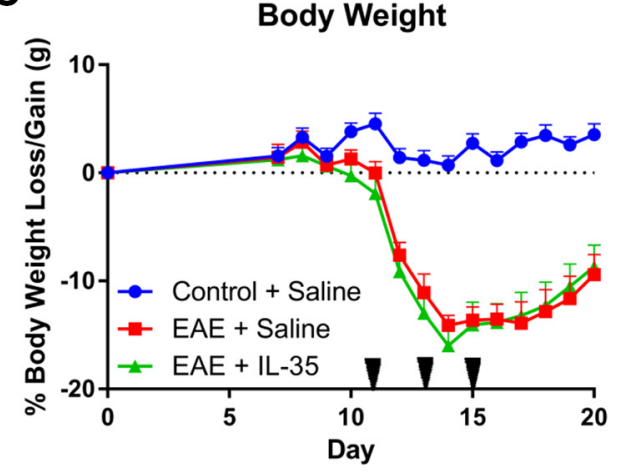

E

Control + Saline

$E A E$ + Saline

$E A E+I L-35$

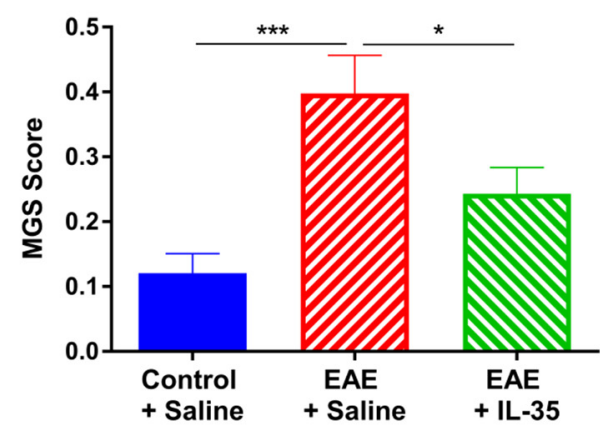

Figure 10. EAE disease progression and pain behaviors following intrathecal IL-35 therapy. A, Levels of IL-35 measured by ELISA in the brain and spinal cord (SC) of control and EAE mice at day 16 after induction. IL-35 was reduced in the SC of EAE mice compared with control mice $\left(n=4-5,{ }^{* * *} p<0.001\right.$, two-way ANOVA with Tukey's post hoc test). $\boldsymbol{B}$, EAE disease progression following intrathecal IL-35 therapy. A reduction in EAE clinical scores was seen on days 19 and 20 after induction in EAE mice injected with IL-35 compared with EAE mice injected with saline $(n=10-11)$. ${ }^{*} p<0.05,{ }^{* *} p<0.01$, repeated measures two-way ANOVA with Tukey's post hoc test. C, Percentage body weight loss/gain recorded following intrathecal IL-35 therapy. Black arrowheads represent time points at which IL-35 was injected intrathecally (days 11,13 , and 15 after induction) ( $n=10-11)$. D, Facial allodynia observed over the course of chronic EAE. On days 12 , 14, and 16 after induction, a decrease in facial allodynia was observed in EAE mice injected with IL-35 compared with EAE mice injected with saline $(n=10-11)$. ${ }^{* * * *} p<0.0001$ signifies a significant difference between control and EAE + saline groups, $\wedge \wedge \wedge \wedge p<0.0001$ signifies a significant difference between control and EAE + IL-35 groups, and \#p $<0.05$ signifies a significant difference between EAE + saline and EAE + IL-35 groups, Kruskal-Wallis test with Dunn's post hoc test and Holm-Bonferroni correction for multiple comparisons. E, Facial grimacing observed on day 19 after induction. A decreased MGS score was seen in EAE mice injected with IL-35 compared with EAE mice injected with saline. An increased MGS score was also seen in EAE mice injected with saline compared with control mice $(n=10-11) .{ }^{*} p<0.05,{ }^{* * *} p<0.001$, one-way ANOVA with Tukey's post hoc test. ELISA, EAE clinical scores, body weight, and MGS data are expressed as mean \pm SEM, whereas facial allodynia data are expressed as box-and-whisker plots in which box limits show the first and third quartile, the center line is the median, and the whiskers represent the minimum and maximum values.

mice with EAEnp increases facial allodynia. This result is consistent with previous studies showing that depletion of Treg cells using anti-CD25 (Austin et al., 2012) or DEREG mice (Lees et al., 2015) results in increased mechanical hypersensitivity in mouse models of peripheral nerve injury.

Similar to previous studies using freshly sorted, nonactivated $\mathrm{CD} 4{ }^{+} \mathrm{CD} 25^{+}$Treg cells (Zhang et al., 2004; McGeachy et al., 2005), activated FoxP $3^{+}$Treg cells injected systemically before
EAE induction suppressed clinical EAE. We show here that systemically delivered activated Treg cells decrease both stimulusevoked (facial allodynia) and spontaneous (facial grimacing) pain behaviors in EAE mice. Intrathecal injection of Treg cells at disease onset had no effect on disease progression, presumably due to the fact that EAE was already established in the CNS or the number of cells injected was insufficient. Intriguingly, Treg cells injected intrathecally reduced facial allodynia in recipient mice 
A

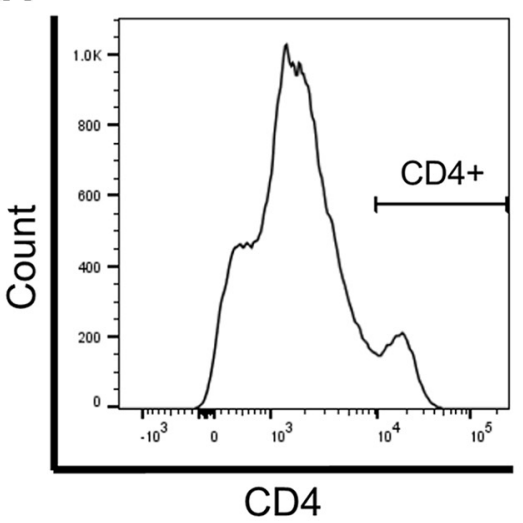

D

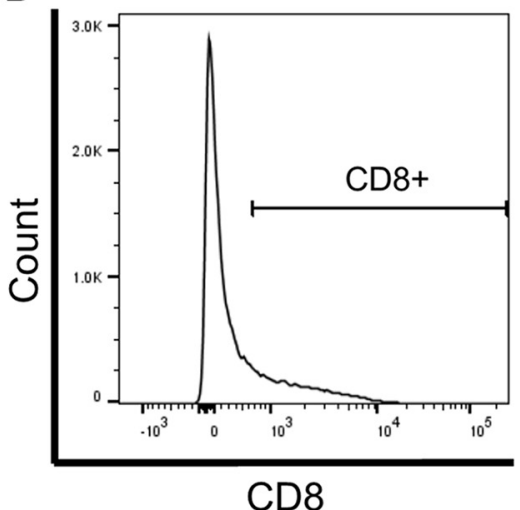

G

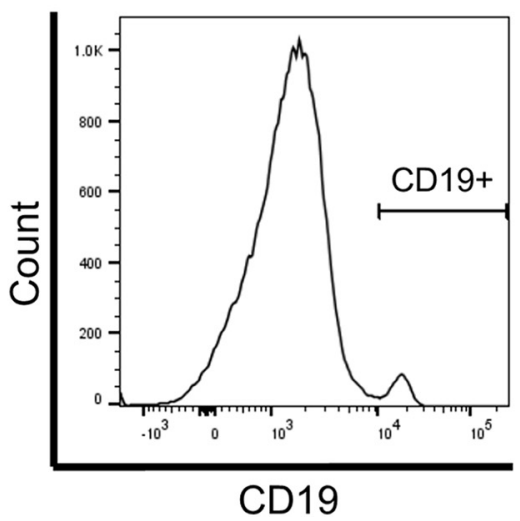

B

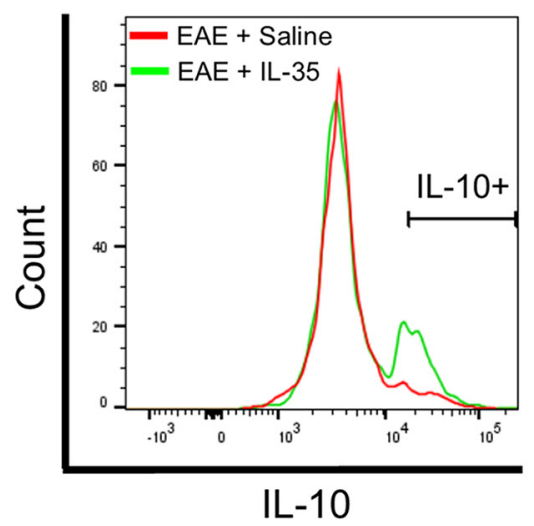

E

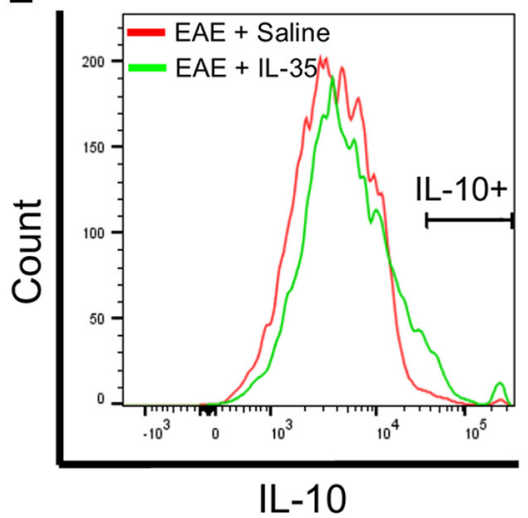

H

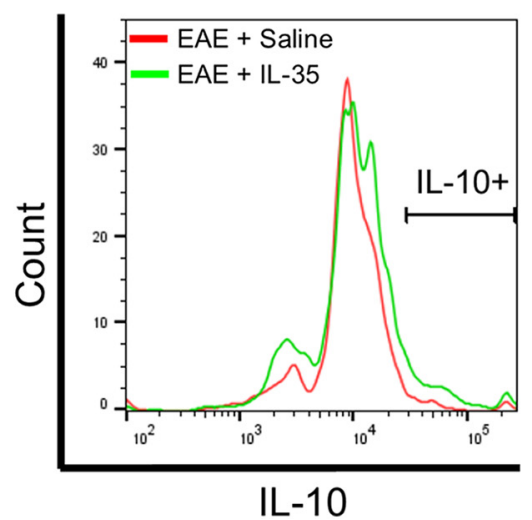

C

CD4+IL-10+

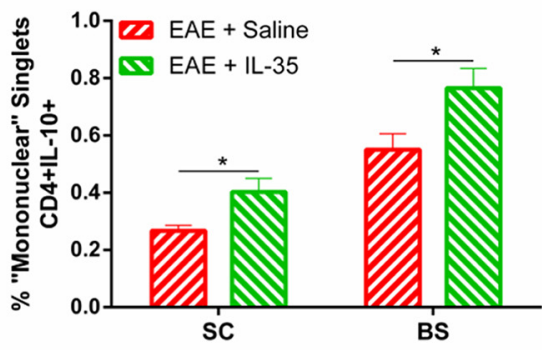

F

CD8+IL-10+

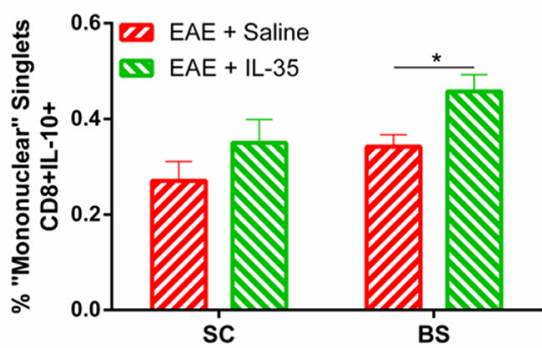

I

CD19+IL-10+

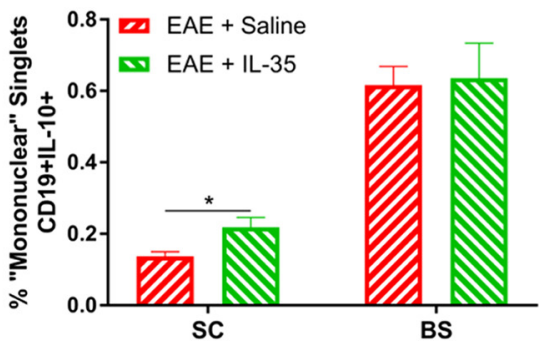

Figure 11. Changes in IL-10-expressing lymphocytes following intrathecal IL-35 therapy in EAE. Flow cytometry was performed on the spinal cord and brainstem of IL-35-treated and control mice on day 16 after EAE induction. Representative histograms showing $\mathrm{CD}^{+}{ }^{+}$cell gating $(A)$, which was subsequently analyzed for IL-10 expression in EAE + saline (red line) and EAE + IL-35 (green line) mice (B). C, Bar graph showing increases in IL-10-expressing CD4 ${ }^{+}$cells in the spinal cord (SC) and brainstem (BS) in EAE mice injected with IL-35 compared with EAE mice injected with saline. Representative histograms show $\mathrm{CD}^{+}{ }^{+}$cell gating $(\boldsymbol{D})$, which was subsequently analyzed for IL-10 expression in EAE + saline (red line) and EAE + IL-35 (green line) mice (E). $\boldsymbol{F}$, Bar graph showing an increase in IL-10-expressing CD8 ${ }^{+}$cells in the BS in EAE mice injected with IL-35 compared with EAE mice injected with saline. Representative histograms show CD19 ${ }^{+}$cell gating $(\mathbf{G})$, which was subsequently analyzed for IL-10 expression in EAE + saline (red line) and EAE + IL-35 (green line) mice $(\boldsymbol{H}) . \boldsymbol{I}$, Bar graph showing an increase in IL-10-expressing CD19 ${ }^{+}$cells in the SC in EAE mice injected with IL-35 compared with EAE mice injected with saline. ${ }^{*} p<0.05$, unpaired Student's $t$ test, $n=6-7$. Data are expressed as mean \pm SEM.

despite no change in clinical EAE. Similar to other EAE studies (Duffy et al., 2016; Frezel et al., 2016; Wang et al., 2017), our findings further support the idea that pain behaviors are independent of clinical severity in EAE. Additionally, our results are consistent with a previous report demonstrating that intrathecal injection of $\mathrm{CD} 4{ }^{+} \mathrm{CD} 25^{+}$Treg cells relieves mechanical allodynia in mice treated with the chemotherapeutic paclitaxel (Liu et al., 2014). We saw no change in facial grimacing, which may reflect differential mechanisms for spontaneous and stimulusevoked pain in EAE (Duffy et al., 2016).

Previous studies have reported links between inflammatory responses in the trigeminal nuclei and evoked pain behaviors in EAE (Duffy et al., 2016; Thorburn et al., 2016). Three weeks after intrathecal injection of Treg cells (i.e., day 32 after EAE induction), we saw a decrease in astrocyte activation in the trigeminal nuclei. Astrocyte activation has long been known to potentiate 

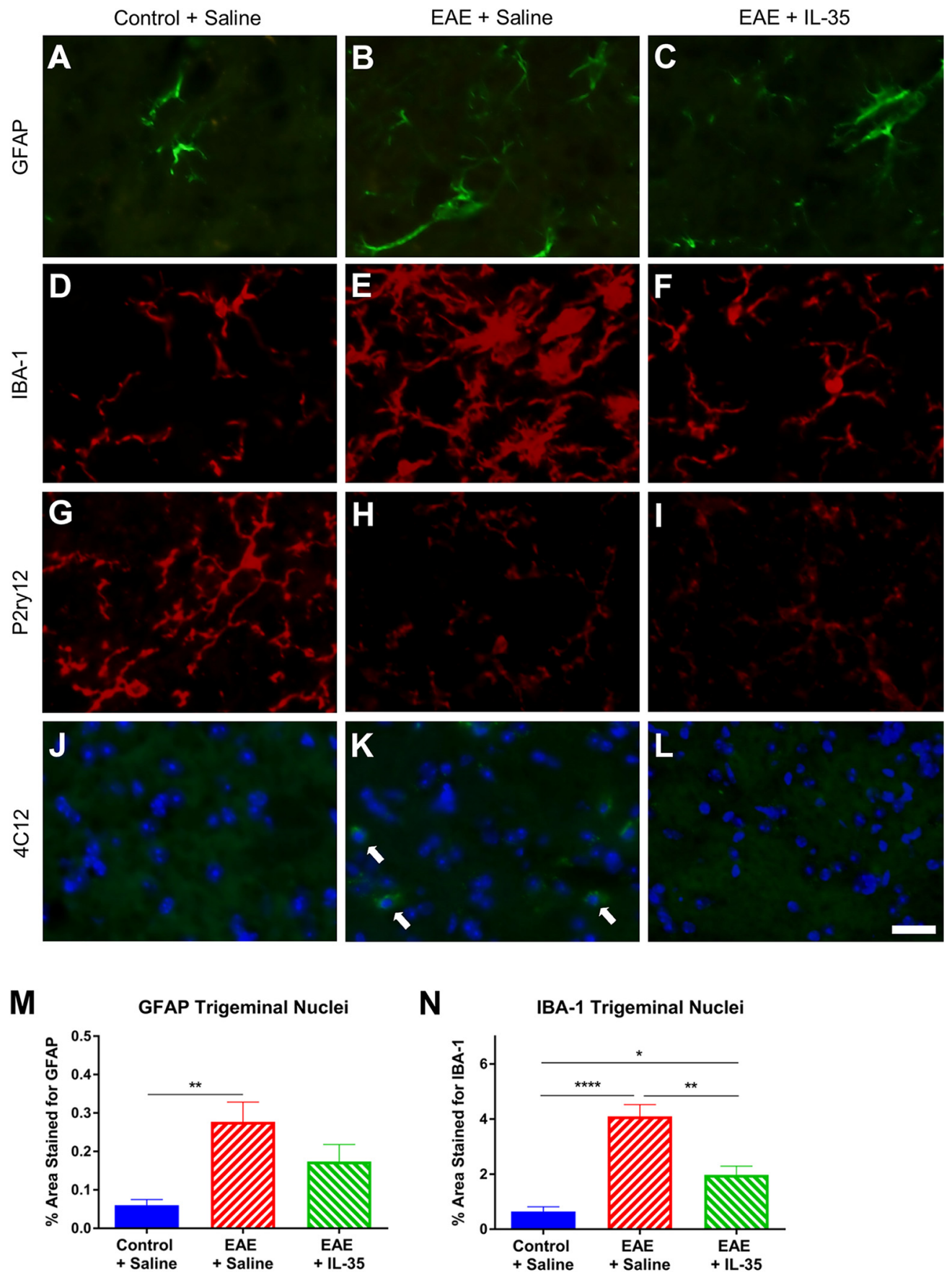

N IBA-1 Trigeminal Nuclei
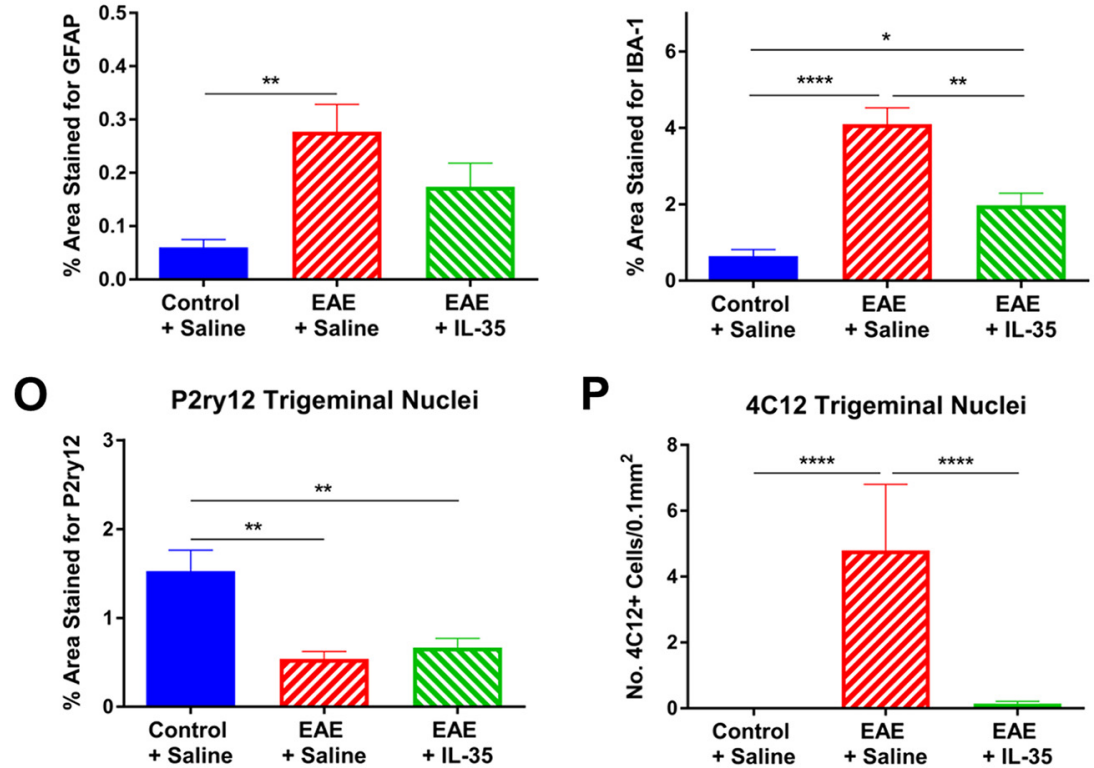

$\mathbf{P}$

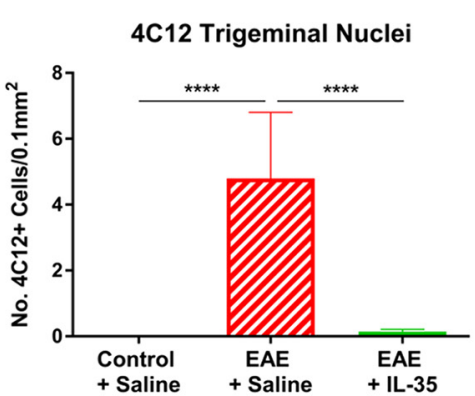

Figure 12. Changes in astrocyte and macrophage/microglia expression and monocyte infiltration following intrathecal IL-35 therapy in EAE. Immunohistochemistry was performed on the trigeminal nuclei in IL-35-treated and control mice on day 20 after EAE induction. Representative images of GFAP (activated astrocytes; $\boldsymbol{A}-\boldsymbol{C}$, IBA-1 (monocytes/microglia; $\boldsymbol{D}-\boldsymbol{F}$ ), P2ry 12 (homeostatic resident microglia; $\mathbf{G}-\boldsymbol{I}$ ), and $4(12$ (infiltrating monocytes; $\boldsymbol{J}-\boldsymbol{L}$ ) staining performed on the trigeminal nuclei in control mice injected with saline, EAE mice injected with saline, and EAE mice injected with IL-35. Scale bar, $25 \mu \mathrm{m} . \mathbf{M}$, Bar graph showing increased levels of GFAP immunostaining in EAE mice injected with saline compared with control mice injected with saline. $\boldsymbol{N}$, Bar graph showing increased IBA-1 immunostaining in EAE mice injected with saline and EAE mice injected with IL-35 compared with control mice injected with saline. (Figure legend continues.) 

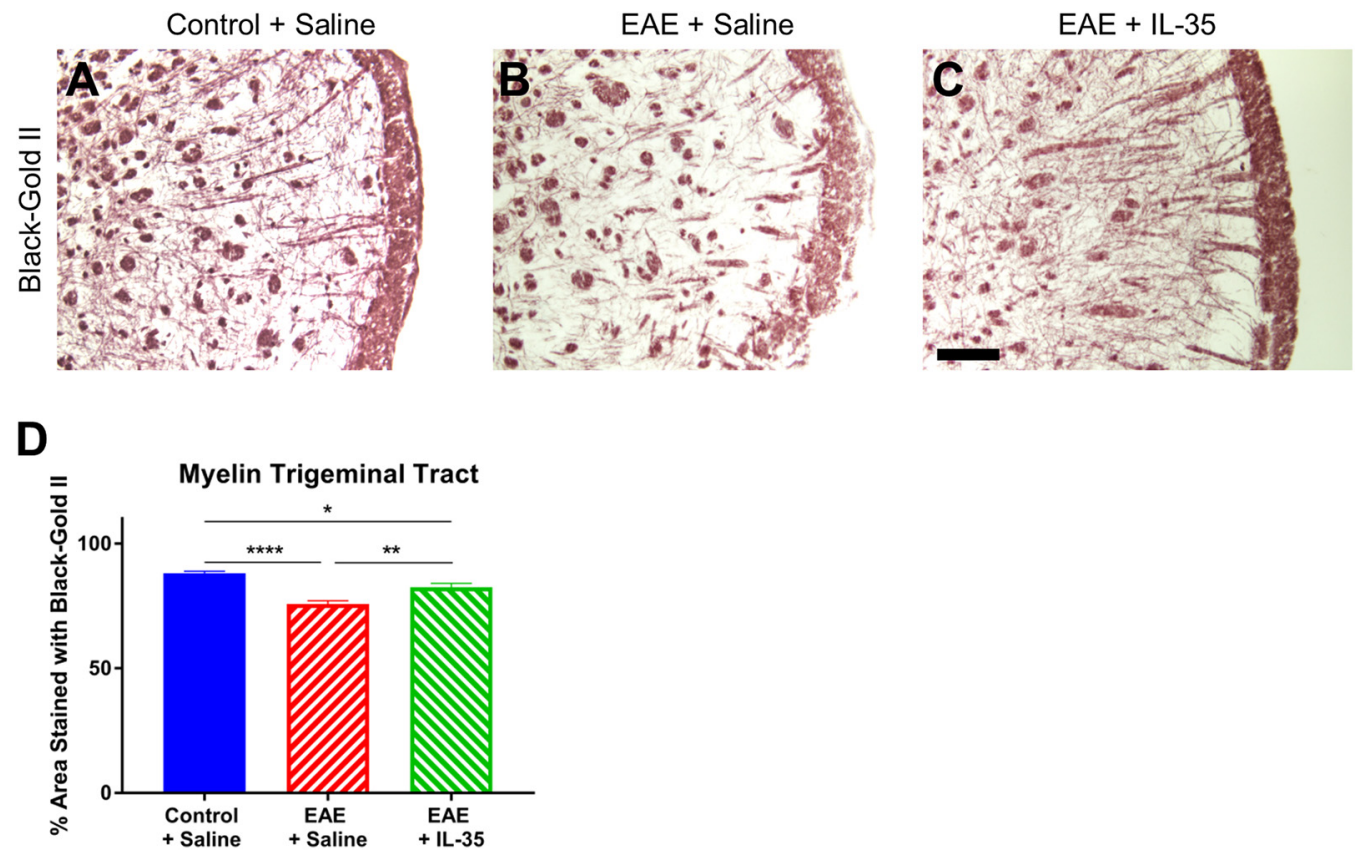

Figure 13. Increased myelination in the spinal trigeminal tract following intrathecal IL-35 therapy in EAE. Myelin staining was performed on the spinal trigeminal tract in IL-35-treated and control mice on day 32 after EAE induction. Representative images of Black-Gold II (myelin; $A-C$ ) staining performed on the spinal trigeminal tract in control mice injected with saline, EAE mice injected with saline, and EAE mice injected with IL-35. Large myelinated tracts are stained dark red-brown. Scale bar, $100 \mu \mathrm{m}$. D, Bar graph showing decreased levels of Black-Gold II staining in EAE mice injected with saline compared with control mice injected with saline and increased levels of staining in EAE mice injected with IL-35 compared with EAE mice injected with saline. ${ }^{*} p<0.05$, ${ }^{* *} p<0.01,{ }^{* * * *} p<0.0001$, one-way ANOVA with Tukey's post hoc test, $n=5$. Data are expressed as mean \pm SEM.

pain behaviors in a range of animal models (Tsuda et al., 2011; Ji et al., 2013; Chen et al., 2014; Nam et al., 2016) and a reduction in astrogliosis may have contributed to the inhibition of facial allodynia seen in our study. Demyelination contributes to neuropathic pain (Gillespie et al., 2000; Zhu et al., 2012) and recent animal studies have shown that ablation of oligodendrocytes facilitates the development of pain behaviors (Gritsch et al., 2014), whereas Treg cells promote myelin regeneration in the CNS independent of their immunoregulatory function (Dombrowski et al., 2017). Intrathecal injection of Treg cells increased myelination of the spinal trigeminal tract in EAE mice. Although this effect was modest, it suggests a potential regenerative or protective effect of Treg cells on oligodendrocytes in addition to their effect on astrogliosis, which may be mediated through production of CCN3, a known mediator of oligodendrocyte differentiation and myelination (Dombrowski et al., 2017). Whether damaged axons in the trigeminal afferent pathway or additional white matter tracts are primary contributors to pain behaviors in the EAE model has yet to be elucidated.

IL-35 is a primary cytokine produced by Treg cells (Collison et al., 2007) and it appears necessary for Treg-cell contactindependent suppression of conventional T cells in vitro (Collison et al., 2009). Examination of IL-35 protein in CNS tissue of EAE mice revealed that IL-35 levels were decreased in the spinal

(Figure legend continued.) A decrease in IBA-1 immunostaining was seen in EAE mice injected with IL-35 compared with EAE mice injected with saline. 0 , Bar graph showing decreased P2ry12 immunostaining in EAE mice injected with saline and EAE mice injected with IL-35 compared with control mice injected with saline. $P$, Bar graph showing an increase in $4 \mathrm{Cl2}^{+}$ cell numbers in EAE mice injected with saline compared with control mice injected with saline and a decrease in $4 \mathrm{C}^{2} 2^{+}$cell numbers in EAE mice injected with IL-35 compared with EAE mice injected with saline. ${ }^{*} p<0.05,{ }^{* *} p<0.01,{ }^{* * *} p<0.0001$, one-way ANOVA with Tukey's post hoc test, $n=5$. Data are expressed as mean \pm SEM. cord compared with control mice. Intrathecal IL-35 therapy commenced at the clinical onset of EAE was sufficient to cause a subtle but significant decrease in EAE severity, presumably because the therapy was withheld until after CNS disease was already established. Our result is consistent with a recent study showing limited effects of intracisternal delivery of an IL-35 gene therapy on EAE disease progression (Casella et al., 2017). Despite this, intrathecal IL-35 therapy was able to significantly reduce spontaneous pain and transiently reduced facial allodynia in EAE mice. Fc fusion proteins such as the recombinant mouse IL-35 used in this study have been reported to have a plasma half-life in the range of 2-3 h (Unverdorben et al., 2016), which may explain the short-lived analgesic effect of intrathecally injected IL-35 in EAE. Future studies aiming to investigate the fate of intrathecally injected IL-35 and to uncover more sustained methods of delivery are warranted.

Intrathecal IL-35 therapy increased numbers of IL-10expressing CD $4{ }^{+} \mathrm{T}$ cells, $\mathrm{CD} 8{ }^{+} \mathrm{T}$ cells, and $\mathrm{CD} 19^{+} \mathrm{B}$ cells in the CNS. This is consistent with previous studies in multiple animal models of autoimmune disease showing that systemic IL-35 therapy increases IL-10 expression in CD4 ${ }^{+} \mathrm{T}$ cells (Zhang et al., 2016; Zhao et al., 2017), Treg cells (Niedbala et al., 2007; Kochetkova et al., 2010; Singh et al., 2015), and B cells (Wang et al., 2014; Cai et al., 2015) in peripheral lymphatic tissues. Intrathecal injection of a plasmid encoding IL-10 at the onset of clinical EAE in rats suppresses clinical disease and pain behaviors (Sloane et al., 2009; Grace et al., 2017), so it is feasible that the increase in IL-10-expressing T and B cells in the CNS may have contributed to the observed amelioration of EAE and associated pain seen in this study. Importantly, $\mathrm{CD} 4^{+}$and $\mathrm{CD} 8^{+} \mathrm{T}$ cells expressing IL-10 were increased in the brainstem of IL-35-treated EAE mice, where it is possible they contributed to modulation of nociceptive trigeminal afferent pathways and, consequently, reduced facial allodynia. 
A

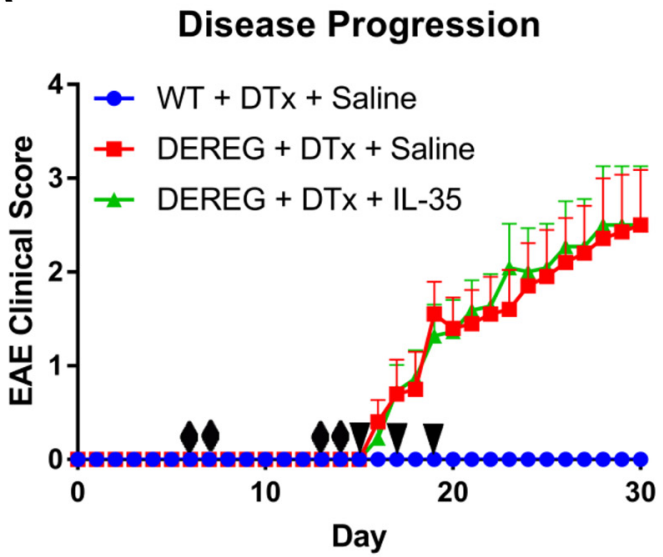

B

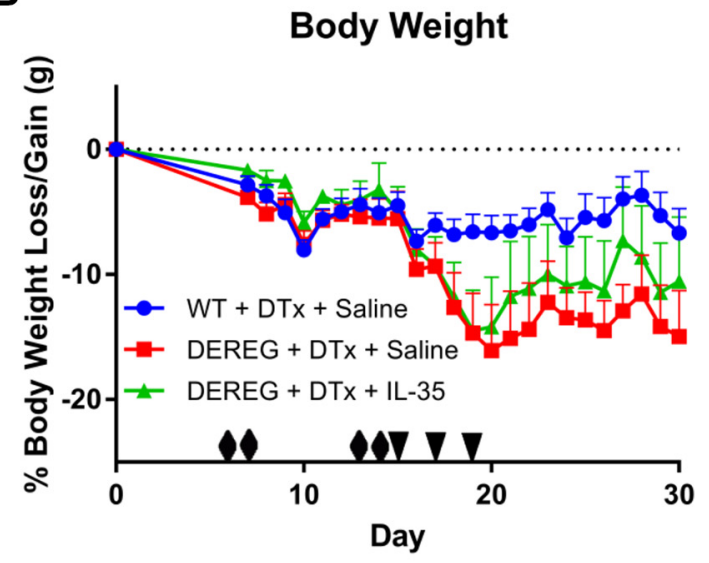

C

Facial Allodynia

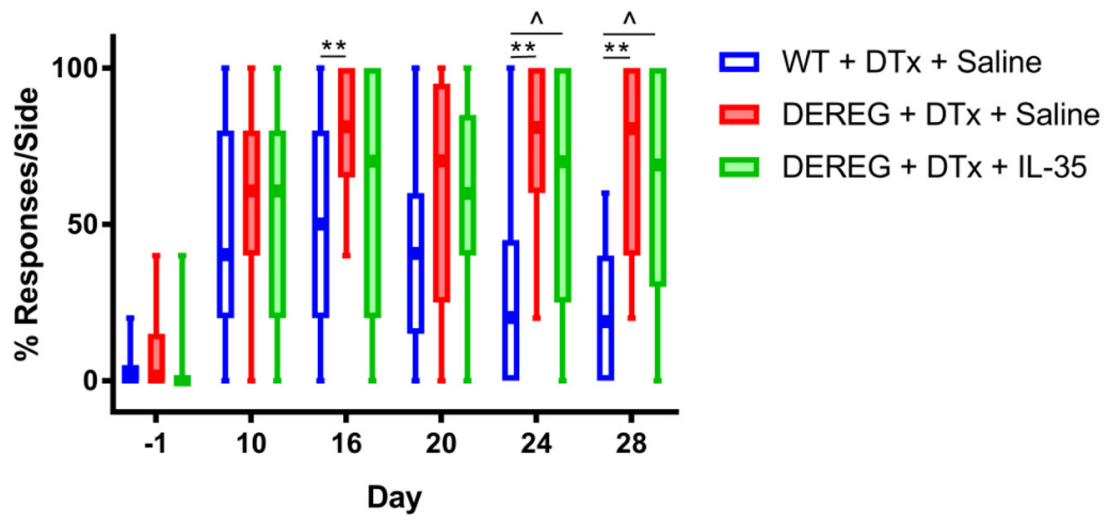

D

MGS Day 20

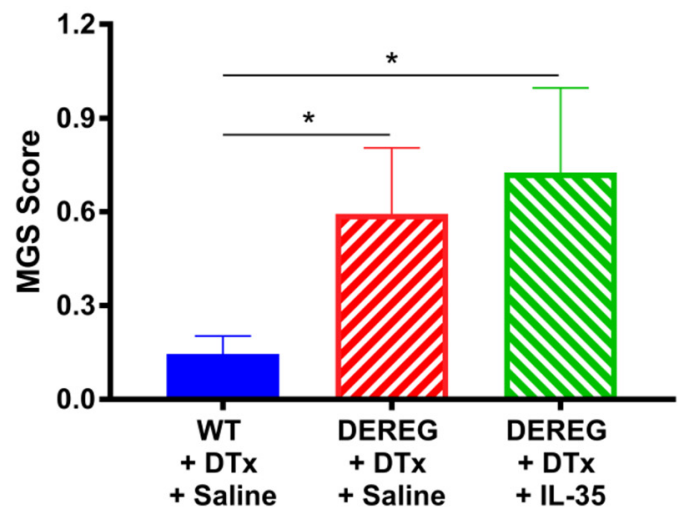

Figure 14. EAEnp disease progression and facial allodynia in DEREG mice following intrathecal IL-35 therapy. A, EAEnp disease progression following DTx injection and intrathecal IL-35 or saline in WT and DEREG mice. B, Percentage body weight loss/gain recorded following DTx injection and intrathecal IL-35 or saline in WT and DEREG mice. Black diamonds represent time points at which DTx was injected intraperitoneally (days 6, 7, 13, and 14 after induction) and black arrowheads represent time points at which IL-35 or saline was injected intrathecally (days 15,17 , and 19 after induction). C, Facial allodynia observed in mice immunized with EAEnp. On days 16, 24, and 28 after induction, an increase in facial allodynia was observed in DEREG mice with EAEnp injected with DTx and given intrathecal saline compared with WT mice with EAEnp injected with DTx and given intrathecal saline. On day 24 and 28 , an increase in facial allodynia was also seen in DEREG mice with EAEnp injected with DTx and given intrathecal IL-35 compared with WT mice with EAEnp injected with DTx and given intrathecal saline $\left(n=7-13\right.$ from 2 replicates). ${ }^{* *} p<0.01$ signifies a significant difference between WT + DTx + saline and DEREG + DTx + saline groups, $\wedge p<0.05$ signifies a significant difference between WT + DTx + saline and DEREG + DTx + IL-35 groups, Kruskal-Wallis test with Dunn's post hoc test and Holm-Bonferroni correction for multiple comparisons. D, Facial grimacing observed on day 20 after induction. An increased MGS score was seen in DEREG mice with EAEnp injected with DTx and given intrathecal saline and DEREG mice with EAEnp injected with DTx and given intrathecal IL-35 compared with WT mice with EAEnp injected with DTx and given intrathecal saline $(n=4-6) .{ }^{*} p<0.05$, one-way ANOVA with Tukey's post hoc test. EAE clinical scores, body weight, and MGS data are expressed as mean \pm SEM, whereas facial allodynia data are expressed as box-and-whisker plots in which box limits show the first and third quartile, the center line is the median, and the whiskers represent the minimum and maximum values. 
P2ry $12^{+}$homeostatic microglia were unchanged following IL-35 treatment, but were reduced in the trigeminal nuclei of EAE mice. Spinal P2ry12 expression has also been shown to be reduced in mouse models of amyotrophic lateral sclerosis (ALS) (Butovsky et al., 2015) and chemotherapy-induced peripheral neuropathy (Makker et al., 2017), suggesting that microglia lose aspects of their homeostatic function during CNS insult. P2ry12expressing homeostatic microglia are reduced in the normalappearing white matter in MS compared with controls and P2ry12 expression is completely lost in active and slowly expanding MS lesions. Conversely, inactive lesions are characterized by a reduced density of microglia/macrophages and conversion of microglia to a P2ry12 ${ }^{+}$homeostatic phenotype (Zrzavy et al., 2017). Analysis of 4C12, a marker specific for monocytes (Butovsky et al., 2014; Bisht et al., 2016), revealed a decrease in the trigeminal nuclei of IL-35-treated EAE mice compared with saline-injected EAE mice. This suggests that a reduction in monocyte recruitment and/or non-homeostatic P2ry12-negative microglia numbers may be responsible for the reduction in total IBA- $1^{+}$cells seen in IL-35-injected EAE mice. Given that macrophages/microglia and their mediators are known to facilitate pain (Jin et al., 2003; Svensson et al., 2003; Tsuda et al., 2003; Ulmann et al., 2008; Hackel et al., 2013; Old et al., 2014; Trevisan et al., 2016), a decrease in their presence in the trigeminal nuclei may have played a role in the reduction of facial allodynia.

We also observed a small but significant increase in myelination of the spinal trigeminal tract in EAE mice following IL-35 treatment, suggesting that centrally delivered IL- 35 has protective or regenerative effects on oligodendrocytes, which is likely mediated through Treg cells. However, it is unknown whether Treg cells or IL-35 have effects on the extent of underlying axonal damage in EAE. Treatment with intrathecal IL-35 was unable to reduce pain behaviors in Treg-cell-depleted DEREG mice with EAEnp, suggesting that the analgesic effect of IL-35 is mediated through functional Treg cells. Indeed, Casella et al. (2017) recently demonstrated that intracisternal delivery of IL-35 gene therapy increases FoxP3 mRNA in CNS-infiltrating T cells in mice with EAE. Interestingly, this was associated with reduced inflammatory infiltrates, but no change in myelination of the spinal cord. Furthermore, because similar behavioral and functional effects were observed after Treg and IL-35 therapy, it would be worth investigating in future studies whether the level of IL-35 is altered following ablation or adoptive transfer of Treg cells in EAE.

In summary, our results highlight the therapeutic potential of Treg cells and IL-35 in suppressing the pain associated with EAE independently of the motor symptoms. Several clinical trials involving adoptive transfer of ex vivo-activated Treg cells have demonstrated safety and efficacy in patients with graft versus host disease (Trzonkowski et al., 2009; Brunstein et al., 2011), type 1 diabetes (Marek-Trzonkowska et al., 2012; Bluestone et al., 2015), refractory Crohn's disease (Desreumaux et al., 2012), and ALS (Alsuliman et al., 2016). Both adoptive transfer of autologous Treg cells and IL-35 therapy provide exciting prospects for the treatment of pain in MS, a largely misunderstood affliction severely lacking in terms of efficacious treatment options.

\section{References}

Aicher SA, Silverman MB, Winkler CW, Bebo BF Jr (2004) Hyperalgesia in an animal model of multiple sclerosis. Pain 110:560-570.

Alsuliman A, Appel SH, Beers DR, Basar R, Shaim H, Kaur I, Zulovich J, Yvon E, Muftuoglu M, Imahashi N, Kondo K, Liu E, Shpall EJ, Rezvani K (2016) A robust, good manufacturing practice-compliant, clinical-scale procedure to generate regulatory $\mathrm{T}$ cells from patients with amyotrophic lateral sclerosis for adoptive cell therapy. Cytotherapy 18:1312-1324.

Austin PJ, Kim CF, Perera CJ, Moalem-Taylor G (2012) Regulatory T cells attenuate neuropathic pain following peripheral nerve injury and experimental autoimmune neuritis. Pain 153:1916-1931.

Bisht K, Sharma KP, Lecours C, Sánchez MG, El Hajj H, Milior G, OlmosAlonso A, Gómez-Nicola D, Luheshi G, Vallières L, Branchi I, Maggi L, Limatola C, Butovsky O, Tremblay MÈ (2016) Dark microglia: a new phenotype predominantly associated with pathological states. Glia 64:826-839.

Bluestone JA, Buckner JH, Fitch M, Gitelman SE, Gupta S, Hellerstein MK, Herold KC, Lares A, Lee MR, Li K, Liu W, Long SA, Masiello LM, Nguyen V, Putnam AL, Rieck M, Sayre PH, Tang Q (2015) Type 1 diabetes immunotherapy using polyclonal regulatory $\mathrm{T}$ cells. Sci Transl Med 7:315ra189.

Browning V, Joseph M, Sedrak M (2012) Multiple sclerosis: a comprehensive review for the physician assistant. JAAPA 25:24-49.

Brunstein CG, Miller JS, Cao Q, McKenna DH, Hippen KL, Curtsinger J, Defor T, Levine BL, June CH, Rubinstein P, McGlave PB, Blazar BR, Wagner JE (2011) Infusion of ex vivo expanded T regulatory cells in adults transplanted with umbilical cord blood: safety profile and detection kinetics. Blood 117:1061-1070.

Butovsky O, Jedrychowski MP, Cialic R, Krasemann S, Murugaiyan G, Fanek Z, Greco DJ, Wu PM, Doykan CE, Kiner O, Lawson RJ, Frosch MP, Pochet N, Fatimy RE, Krichevsky AM, Gygi SP, Lassmann H, Berry J, Cudkowicz ME, Weiner HL (2015) Targeting miR-155 restores abnormal microglia and attenuates disease in SOD1 mice. Ann Neurol 77:7599.

Butovsky O, Jedrychowski MP, Moore CS, Cialic R, Lanser AJ, Gabriely G, Koeglsperger T, Dake B, Wu PM, Doykan CE, Fanek Z, Liu L, Chen Z, Rothstein JD, Ransohoff RM, Gygi SP, Antel JP, Weiner HL (2014) Identification of a unique TGF-beta-dependent molecular and functional signature in microglia. Nat Neurosci 17:131-143.

Cai Z, Wong CK, Dong J, Chu M, Jiao D, Kam NW, Lam CW, Tam LS (2015) Remission of systemic lupus erythematosus disease activity with regulatory cytokine interleukin (IL)-35 in Murphy Roths Large (MRL)/lpr mice. Clin Exp Immunol 181:253-266.

Casella G, Finardi A, Descamps H, Colombo F, Maiorino C, Ruffini F, Patrone M, Degano M, Martino G, Muzio L, Becher B, Furlan R (2017) IL-27, but not IL-35, inhibits neuroinflammation through modulating GM-CSF expression. Sci Rep 7:16547.

Chen G, Park CK, Xie RG, Berta T, Nedergaard M, Ji RR (2014) Connexin-43 induces chemokine release from spinal cord astrocytes to maintain late-phase neuropathic pain in mice. Brain 137:2193-2209.

Collison LW, Vignali DA (2008) Interleukin-35: odd one out or part of the family? Immunol Rev 226:248-262.

Collison LW, Chaturvedi V, Henderson AL, Giacomin PR, Guy C, Bankoti J, Finkelstein D, Forbes K, Workman CJ, Brown SA, Rehg JE, Jones ML, Ni HT, Artis D, Turk MJ, Vignali DA (2010) IL-35-mediated induction of a potent regulatory T cell population. Nat Immunol 11:1093-1101.

Collison LW, Pillai MR, Chaturvedi V, Vignali DA (2009) Regulatory T cell suppression is potentiated by target $\mathrm{T}$ cells in a cell contact, IL-35- and IL-10-dependent manner. J Immunol 182:6121-6128.

Collison LW, Workman CJ, Kuo TT, Boyd K, Wang Y, Vignali KM, Cross R, Sehy D, Blumberg RS, Vignali DA (2007) The inhibitory cytokine IL-35 contributes to regulatory T-cell function. Nature 450:566-569.

Dendrou CA, Fugger L, Friese MA (2015) Immunopathology of multiple sclerosis. Nat Rev Immunol 15:545-558.

Desreumaux P, Foussat A, Allez M, Beaugerie L, Hébuterne X, Bouhnik Y, Nachury M, Brun V, Bastian H, Belmonte N, Ticchioni M, Duchange A, Morel-Mandrino P, Neveu V, Clerget-Chossat N, Forte M, Colombel JF (2012) Safety and efficacy of antigen-specific regulatory T-cell therapy for patients with refractory Crohn's disease. Gastroenterology 143:12071217.e2.

Dixon KO, van der Kooij SW, Vignali DA, van Kooten C (2015) Human tolerogenic dendritic cells produce IL-35 in the absence of other IL-12 family members. Eur J Immunol 45:1736-1747.

Dombrowski Y, O’Hagan T, Dittmer M, Penalva R, Mayoral SR, Bankhead P, Fleville S, Eleftheriadis G, Zhao C, Naughton M, Hassan R, Moffat J, Falconer J, Boyd A, Hamilton P, Allen IV, Kissenpfennig A, Moynagh PN, Evergren E, Perbal B, et al. (2017) Regulatory T cells promote myelin regeneration in the central nervous system. Nat Neurosci 20:674-680. 
Drulovic J, Basic-Kes V, Grgic S, Vojinovic S, Dincic E, Toncev G, Kezic MG, Kisic-Tepavcevic D, Dujmovic I, Mesaros S, Miletic-Drakulic S, Pekmezovic T (2015) The prevalence of pain in adults with multiple sclerosis: a multicenter cross-sectional survey. Pain Med 16:1597-1602.

Duffy SS, Keating BA, Perera CJ, Moalem-Taylor G (2018a) The role of regulatory $\mathrm{T}$ cells in nervous system pathologies. J Neurosci Res 96:951-968.

Duffy SS, Lees JG, Perera CJ, Moalem-Taylor G (2018b) Managing neuropathic pain in multiple sclerosis: pharmacological interventions. Med Chem 14:106-119.

Duffy SS, Perera CJ, Makker PG, Lees JG, Carrive P, Moalem-Taylor G (2016) Peripheral and central neuroinflammatory changes and pain behaviors in an animal model of multiple sclerosis. Front Immunol 7:369.

Feketova S, Waczulikova I, Kukumberg P, Mares J (2016) Pain in multiple sclerosis: prevalence and characteristics of various pain conditions. Journal of Multiple Sclerosis 3:3.

Frezel N, Sohet F, Daneman R, Basbaum AI, Braz JM (2016) Peripheral and central neuronal ATF3 precedes CD4 ${ }^{+}$T-cell infiltration in EAE. Exp Neurol 283:224-234.

Gillespie CS, Sherman DL, Fleetwood-Walker SM, Cottrell DF, Tait S, Garry EM, Wallace VC, Ure J, Griffiths IR, Smith A, Brophy PJ (2000) Peripheral demyelination and neuropathic pain behavior in periaxin-deficient mice. Neuron 26:523-531.

Grace PM, Loram LC, Christianson JP, Strand KA, Flyer-Adams JG, Penzkover KR, Forsayeth JR, van Dam AM, Mahoney MJ, Maier SF, Chavez RA, Watkins LR (2017) Behavioral assessment of neuropathic pain, fatigue, and anxiety in experimental autoimmune encephalomyelitis (EAE) and attenuation by interleukin-10 gene therapy. Brain Behav Immun 59:4954.

Gritsch S, Lu J, Thilemann S, Wörtge S, Möbius W, Bruttger J, Karram K, Ruhwedel T, Blanfeld M, Vardeh D, Waisman A, Nave KA, Kuner R (2014) Oligodendrocyte ablation triggers central pain independently of innate or adaptive immune responses in mice. Nat Commun 5:5472.

Hackel D, Pflücke D, Neumann A, Viebahn J, Mousa S, Wischmeyer E, Roewer N, Brack A, Rittner HL (2013) The connection of monocytes and reactive oxygen species in pain. PLoS One 8:e63564.

Haller S, Duval A, Migliorini R, Stevanin M, Mack V, Acha-Orbea H (2017) Interleukin-35-producing CD8alpha ${ }^{+}$dendritic cells acquire a tolerogenic state and regulate $\mathrm{T}$ cell function. Front Immunol 8:98.

Ji RR, Berta T, Nedergaard M (2013) Glia and pain: is chronic pain a gliopathy? Pain 154:S10-S28.

Jin SX, Zhuang ZY, Woolf CJ, Ji RR (2003) p38 mitogen-activated protein kinase is activated after a spinal nerve ligation in spinal cord microglia and dorsal root ganglion neurons and contributes to the generation of neuropathic pain. J Neurosci 23:4017-4022.

Kochetkova I, Golden S, Holderness K, Callis G, Pascual DW (2010) IL-35 stimulation of $\mathrm{CD} 39^{+}$regulatory $\mathrm{T}$ cells confers protection against collagen II-induced arthritis via the production of IL-10. J Immunol 184: $7144-7153$

Korn T, Reddy J, Gao W, Bettelli E, Awasthi A, Petersen TR, Bäckström BT, Sobel RA, Wucherpfennig KW, Strom TB, Oukka M, Kuchroo VK (2007) Myelin-specific regulatory T cells accumulate in the CNS but fail to control autoimmune inflammation. Nat Med 13:423-431.

Koutrolos M, Berer K, Kawakami N, Wekerle H, Krishnamoorthy G (2014) Treg cells mediate recovery from EAE by controlling effector $\mathrm{T}$ cell proliferation and motility in the CNS. Acta Neuropathol Commun 2:163.

Lahl K, Sparwasser T (2011) In vivo depletion of FoxP3 ${ }^{+}$Tregs using the DEREG mouse model. Methods Mol Biol 707:157-172.

Lahl K, Loddenkemper C, Drouin C, Freyer J, Arnason J, Eberl G, Hamann A, Wagner H, Huehn J, Sparwasser T (2007) Selective depletion of Foxp3 ${ }^{+}$ regulatory T cells induces a scurfy-like disease. J Exp Med 204:57-63.

Langford DJ, Bailey AL, Chanda ML, Clarke SE, Drummond TE, Echols S, Glick S, Ingrao J, Klassen-Ross T, Lacroix-Fralish ML, Matsumiya L, Sorge RE, Sotocinal SG, Tabaka JM, Wong D, van den Maagdenberg AM, Ferrari MD, Craig KD, Mogil JS (2010) Coding of facial expressions of pain in the laboratory mouse. Nat Methods 7:447-449.

Lees JG, Duffy SS, Perera CJ, Moalem-Taylor G (2015) Depletion of Foxp $3^{+}$regulatory $\mathrm{T}$ cells increases severity of mechanical allodynia and significantly alters systemic cytokine levels following peripheral nerve injury. Cytokine 71:207-214.

Liu XJ, Zhang Y, Liu T, Xu ZZ, Park CK, Berta T, Jiang D, Ji RR (2014)
Nociceptive neurons regulate innate and adaptive immunity and neuropathic pain through MyD88 adapter. Cell Res 24:1374-1377.

Lu J, Kurejova M, Wirotanseng LN, Linker RA, Kuner R, Tappe-Theodor A (2012) Pain in experimental autoimmune encephalitis: a comparative study between different mouse models. J Neuroinflammation 9:233.

Makker PG, Duffy SS, Lees JG, Perera CJ, Tonkin RS, Butovsky O, Park SB, Goldstein D, Moalem-Taylor G (2017) Characterisation of immune and neuroinflammatory changes associated with chemotherapy-induced peripheral neuropathy. PLoS One 12:e0170814.

Marek-Trzonkowska N, Mysliwiec M, Dobyszuk A, Grabowska M, Techmanska I, Juscinska J, Wujtewicz MA, Witkowski P, Mlynarski W, Balcerska A, Mysliwska J, Trzonkowski P (2012) Administration of CD $4{ }^{+} \mathrm{CD} 25$ high CD127- regulatory $T$ cells preserves beta-cell function in type 1 diabetes in children. Diabetes Care 35:1817-1820.

Matsushita T, Horikawa M, Iwata Y, Tedder TF (2010) Regulatory B cells (B10 cells) and regulatory $\mathrm{T}$ cells have independent roles in controlling experimental autoimmune encephalomyelitis initiation and late-phase immunopathogenesis. J Immunol 185:2240-2252.

McGeachy MJ, Stephens LA, Anderton SM (2005) Natural recovery and protection from autoimmune encephalomyelitis: contribution of $\mathrm{CD} 4{ }^{+} \mathrm{CD} 25^{+}$regulatory cells within the central nervous system. J Immunol 175:3025-3032.

Moalem G, Tracey DJ (2006) Immune and inflammatory mechanisms in neuropathic pain. Brain Res Rev 51:240-264.

Nam Y, Kim JH, Kim JH, Jha MK, Jung JY, Lee MG, Choi IS, Jang IS, Lim DG, Hwang SH, Cho HJ, Suk K (2016) Reversible induction of pain hypersensitivity following optogenetic stimulation of spinal astrocytes. Cell Rep 17:3049-3061.

Niedbala W, Wei XQ, Cai B, Hueber AJ, Leung BP, McInnes IB, Liew FY (2007) IL-35 is a novel cytokine with therapeutic effects against collageninduced arthritis through the expansion of regulatory $\mathrm{T}$ cells and suppression of Th17 cells. Eur J Immunol 37:3021-3029.

Old EA, Nadkarni S, Grist J, Gentry C, Bevan S, Kim KW, Mogg AJ, Perretti M, Malcangio M (2014) Monocytes expressing CX3CR1 orchestrate the development of vincristine-induced pain. J Clin Invest 124:2023-2036.

Olechowski CJ, Truong JJ, Kerr BJ (2009) Neuropathic pain behaviours in a chronic-relapsing model of experimental autoimmune encephalomyelitis (EAE). Pain 141:156-164.

Rodrigues DH, Sachs D, Teixeira AL (2009) Mechanical hypernociception in experimental autoimmune encephalomyelitis. Arq Neuropsiquiatr 67: $78-81$.

Rolak LA (2003) Multiple sclerosis: it's not the disease you thought it was. Clin Med Res 1:57-60.

Schmitz K, Pickert G, Wijnvoord N, Häussler A, Tegeder I (2013) Dichotomy of CCL21 and CXCR3 in nerve injury-evoked and autoimmunityevoked hyperalgesia. Brain Behav Immun 32:186-200.

Shen P, Roch T, Lampropoulou V, O'Connor RA, Stervbo U, Hilgenberg E, Ries S, Dang VD, Jaimes Y, Daridon C, Li R, Jouneau L, Boudinot P, Wilantri S, Sakwa I, Miyazaki Y, Leech MD, McPherson RC, Wirtz S, Neurath M, et al. (2014) IL-35-producing B cells are critical regulators of immunity during autoimmune and infectious diseases. Nature 507: 366-370

Singh K, Kadesjö E, Lindroos J, Hjort M, Lundberg M, Espes D, Carlsson PO, Sandler S, Thorvaldson L (2015) Interleukin-35 administration counteracts established murine type 1 diabetes-possible involvement of regulatory T cells. Sci Rep 5:12633.

Sloane E, Ledeboer A, Seibert W, Coats B, van Strien M, Maier SF, Johnson KW, Chavez R, Watkins LR, Leinwand L, Milligan ED, Van Dam AM (2009) Anti-inflammatory cytokine gene therapy decreases sensory and motor dysfunction in experimental Multiple Sclerosis: MOG-EAE behavioral and anatomical symptom treatment with cytokine gene therapy. Brain Behav Immun 23:92-100.

Svensson CI, Marsala M, Westerlund A, Calcutt NA, Campana WM, Freshwater JD, Catalano R, Feng Y, Protter AA, Scott B, Yaksh TL (2003) Activation of p38 mitogen-activated protein kinase in spinal microglia is a critical link in inflammation-induced spinal pain processing. J Neurochem 86:1534-1544.

Thorburn KC, Paylor JW, Webber CA, Winship IR, Kerr BJ (2016) Facial hypersensitivity and trigeminal pathology in mice with experimental autoimmune encephalomyelitis. Pain 157:627-642.

Trevisan G, Benemei S, Materazzi S, De Logu F, De Siena G, Fusi C, Fortes Rossato M, Coppi E, Marone IM, Ferreira J, Geppetti P, Nassini R (2016) 
TRPA1 mediates trigeminal neuropathic pain in mice downstream of monocytes/macrophages and oxidative stress. Brain 139:1361-1377.

Truini A, Barbanti P, Pozzilli C, Cruccu G (2013) A mechanism-based classification of pain in multiple sclerosis. J Neurol 260:351-367.

Trzonkowski P, Bieniaszewska M, Juścińska J, Dobyszuk A, Krzystyniak A, Marek N, Myśliwska J, Hellmann A (2009) First-in-man clinical results of the treatment of patients with graft versus host disease with human ex vivo expanded $\mathrm{CD} 4{ }^{+} \mathrm{CD} 25^{+} \mathrm{CD} 127$ - T regulatory cells. Clin Immunol 133:22-26.

Tsuda M, Kohro Y, Yano T, Tsujikawa T, Kitano J, Tozaki-Saitoh H, Koyanagi S, Ohdo S, Ji RR, Salter MW, Inoue K (2011) JAK-STAT3 pathway regulates spinal astrocyte proliferation and neuropathic pain maintenance in rats. Brain 134:1127-1139.

Tsuda M, Shigemoto-Mogami Y, Koizumi S, Mizokoshi A, Kohsaka S, Salter MW, Inoue K (2003) P2X4 receptors induced in spinal microglia gate tactile allodynia after nerve injury. Nature 424:778-783.

Ulmann L, Hatcher JP, Hughes JP, Chaumont S, Green PJ, Conquet F, Buell GN, Reeve AJ, Chessell IP, Rassendren F (2008) Up-regulation of P2X4 receptors in spinal microglia after peripheral nerve injury mediates BDNF release and neuropathic pain. J Neurosci 28:11263-11268.

Unverdorben F, Richter F, Hutt M, Seifert O, Malinge P, Fischer N, Kontermann RE (2016) Pharmacokinetic properties of IgG and various Fc fusion proteins in mice. MAbs 8:120-128.

Wang IC, Chung CY, Liao F, Chen CC, Lee CH (2017) Peripheral sensory neuron injury contributes to neuropathic pain in experimental autoimmune encephalomyelitis. Sci Rep 7:42304.

Wang RX, Yu CR, Dambuza IM, Mahdi RM, Dolinska MB, Sergeev YV, Wingfield PT, Kim SH, Egwuagu CE (2014) Interleukin-35 induces regulatory B cells that suppress autoimmune disease. Nat Med 20:633-641.

Wei X, Zhang J, Gu Q, Huang M, Zhang W, Guo J, Zhou X (2017) Reciprocal expression of IL-35 and IL-10 defines two distinct effector Treg subsets that are required for maintenance of immune tolerance. Cell Rep 21:1853-1869.

Xia N, Jiao J, Tang TT, Lv BJ, Lu YZ, Wang KJ, Zhu ZF, Mao XB, Nie SF, Wang Q, Tu X, Xiao H, Liao YH, Shi GP, Cheng X (2015) Activated regulatory T-cells attenuate myocardial ischaemia/reperfusion injury through a CD39-dependent mechanism. Clin Sci (Lond) 128:679-693.

Yuan S, Shi Y, Tang SJ (2012) Wnt signaling in the pathogenesis of multiple sclerosis-associated chronic pain. J Neuroimmune Pharmacol 7:904-913.

Zhang J, Lin Y, Li C, Zhang X, Cheng L, Dai L, Wang Y, Wang F, Shi G, Li Y, Yang Q, Cui X, Liu Y, Wang H, Zhang S, Yang Y, Xiang R, Li J, Yu D, Wei $\mathrm{Y}$, et al. (2016) IL-35 decelerates the inflammatory process by regulating inflammatory cytokine secretion and M1/M2 macrophage ratio in psoriasis. J Immunol 197:2131-2144.

Zhang X, Koldzic DN, Izikson L, Reddy J, Nazareno RF, Sakaguchi S, Kuchroo VK, Weiner HL (2004) IL-10 is involved in the suppression of experimental autoimmune encephalomyelitis by $\mathrm{CD} 25{ }^{+} \mathrm{CD} 4{ }^{+}$regulatory T cells. Int Immunol 16:249-256.

Zhang X, Reddy J, Ochi H, Frenkel D, Kuchroo VK, Weiner HL (2006) Recovery from experimental allergic encephalomyelitis is TGF-beta dependent and associated with increases in $\mathrm{CD} 4{ }^{+} \mathrm{LAP}^{+}$and $\mathrm{CD} 4{ }^{+} \mathrm{CD} 25^{+}$ T cells. Int Immunol 18:495-503.

Zhao N, Li H, Yan Y, Jiang R, He X (2017) Mesenchymal stem cells overexpressing IL-35 effectively inhibit $\mathrm{CD} 4{ }^{+} \mathrm{T}$ cell function. Cell Immunol 312:61-66.

Zhu YL, Xie ZL, Wu YW, Duan WR, Xie YK (2012) Early demyelination of primary A-fibers induces a rapid-onset of neuropathic pain in rat. Neuroscience 200:186-198.

Zrzavy T, Hametner S, Wimmer I, Butovsky O, Weiner HL, Lassmann H (2017) Loss of 'homeostatic' microglia and patterns of their activation in active multiple sclerosis. Brain 140:1900-1913. 